\title{
IS EFFICIENCY ENOUGH? TOWARDS A NEW FRAMEWORK FOR CARBON SAVINGS IN THE CALIFORNIA RESIDENTIAL SECTOR
}

Prepared For:

California Energy Commission

Public Interest Energy Research Program

Prepared By:

Lawrence Berkeley National Laboratory

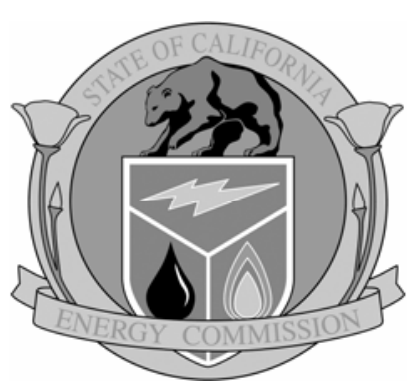

Arnold Schwarzenegger Governor

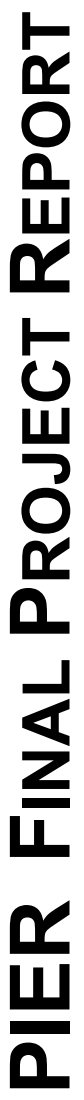

October 2005

CEC-500-2005-162 


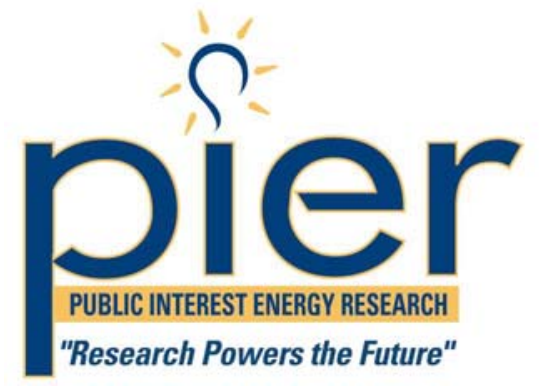

"Research Powers the Future"
Prepared By:

Lawrence Berkeley National Laboratory

Mithra Moezzi

Rick Diamond

Berkeley, California

Contract No. 500-02-004

Work Authorization MRA \#015-003

Prepared For:

California Energy Commission

Public Interest Energy Research (PIER) Program

Gina Barkalow,

Contract Manager

Kelly Birkinshaw,

Program Area Team Lead

Martha Krebs, Ph.D.

Deputy Director

ENERGY RESEARCH AND DEVELOPMENT

DIVISION

B. B. Blevins

Executive Director

\section{DISCLAIMER}

This report was prepared as the result of work sponsored by the California Energy Commission. It does not necessarily represent the views of the Energy Commission, its employees or the State of California. The Energy Commission, the State of California, its employees, contractors and subcontractors make no warrant, express or implied, and assume no legal liability for the information in this report; nor does any party represent that the uses of this information will not infringe upon privately owned rights. This report has not been approved or disapproved by the California Energy Commission nor has the California Energy Commission passed upon the accuracy or adequacy of the information in this report. 


\section{Acknowledgements}

The authors would like to thank several of their colleagues from the Lawrence Berkeley National Laboratory and the University of California for their stimulating input and contributions to this work. These include Reuben Deumling, Jeff Harris, Maithili Iyer, Alan Meier, Alan Sanstad, and Max Sherman. Several other individuals were contacted over the course of this project, and we would like to acknowledge their help: Ann Edminster (Design AVEnues), Glenn Chinery (U.S. Environmental Protection Agency), Bill Pennington (California Energy Commission), Peter

Schneider (Vermont Energy Investment Corporation), and Lisa Stevenson (Pacific Northwest National Laboratory). Several anonymous readers provided useful or encouraging reviews; we thank them. In addition, we would like to thank Edward Vine (University of California Office of the President, California Institute for Energy and the Environment) for his support and contribution to this work.

Please cite this report as follows:

Moezzi, Mithra and Diamond, Rick. 2004. Is Efficiency Enough? Towards a New Framework for Carbon Savings in the California Residential Sector. California Energy Commission, PIER Energy-Related Environmental Research. CEC-500-2005-162. 


\section{Preface}

The Public Interest Energy Research (PIER) Program supports public interest energy research and development that will help improve the quality of life in California by bringing environmentally safe, affordable, and reliable energy services and products to the marketplace.

The PIER Program, managed by the California Energy Commission (Energy Commission), annually awards up to $\$ 62$ million to conduct the most promising public interest energy research by partnering with Research, Development, and Demonstration (RD\&D) organizations, including individuals, businesses, utilities, and public or private research institutions.

PIER funding efforts are focused on the following RD\&D program areas:

- Buildings End-Use Energy Efficiency

- Energy-Related Environmental Research

- Energy Systems Integration

- Environmentally Preferred Advanced Generation

- Industrial/Agricultural/Water End-Use Energy Efficiency

- Renewable Energy Technologies

What follows is the final report for the Is Efficiency Enough? Towards a New Framework for Carbon Savings in the California Residential Sector contract, contract number \#500-02-004MRA \#015-003, conducted by the Lawrence Berkeley National Laboratory. The report is entitled Is Efficiency Enough? Towards a New Framework for Carbon Savings in the California Residential Sector. This project contributes to the Energy-Related Environmental Research program.

For more information on the PIER Program, please visit the Energy Commission's website www.energy.ca.gov/pier/ or contract the Energy Commission at (916) 654-5164. 


\section{Table of Contents}

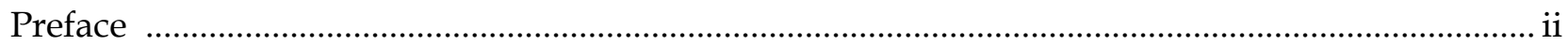

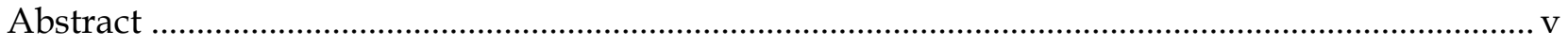

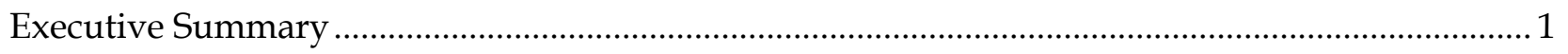

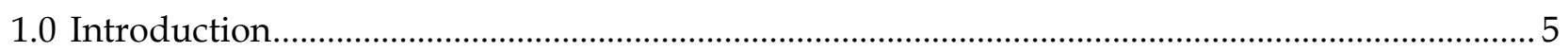

1.1 Background: The Dilemma of Using Efficiency as a Policy Tool for Reducing Carbon

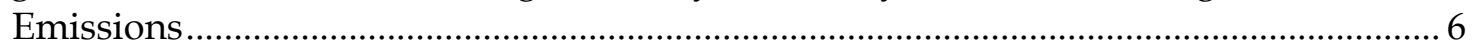

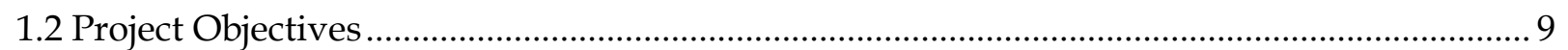

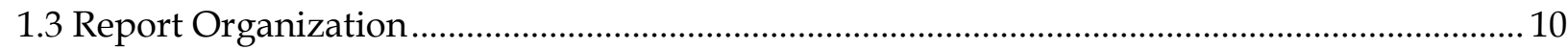

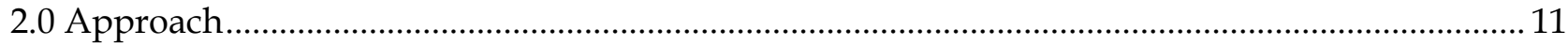

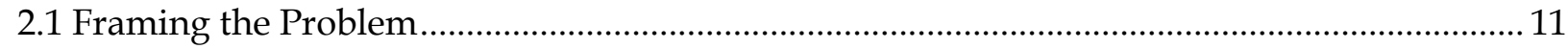

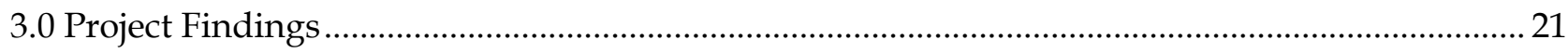

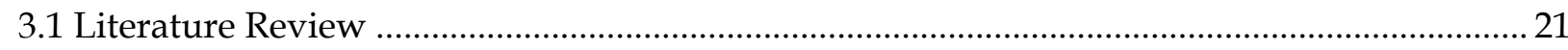

3.2 Overview of California Residential Electricity Consumption............................................... 22

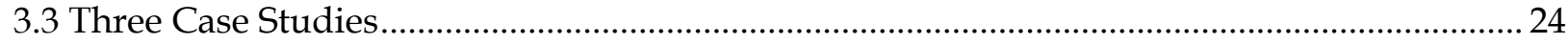

4.0 Policy Considerations, Technical Possibilities, and Recommendations..................................... 47

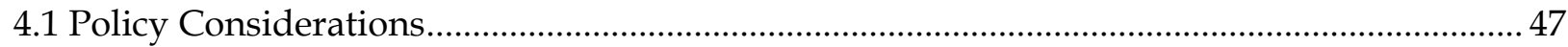

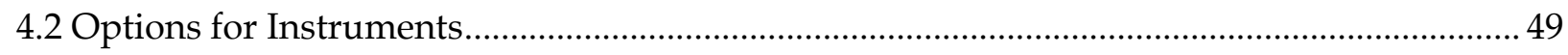

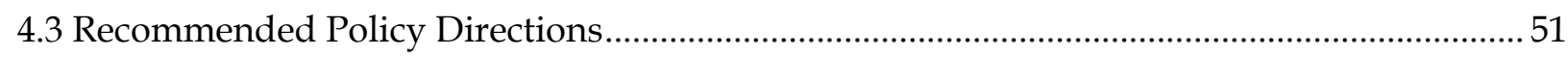

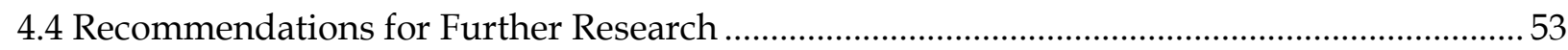

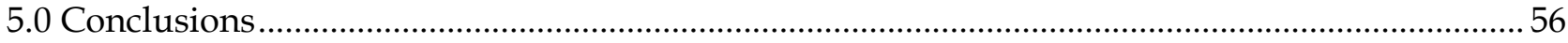

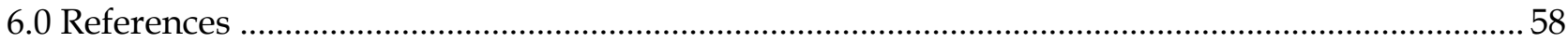

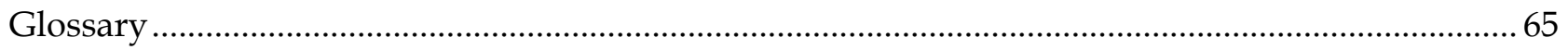




\section{List of Figures}

Figure 1. U.S. carbon emissions (million metric tons carbon equivalent) across all sectors....... 24

Figure 2. U.S. carbon emissions from residential sector energy consumption.......................... 25

Figure 3. U.S. per capita carbon dioxide emissions from residential sector energy consumption

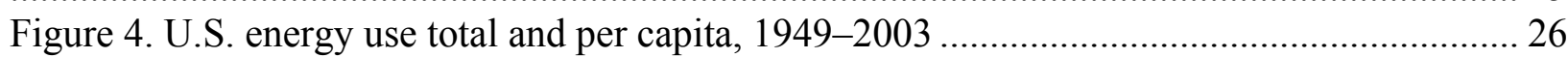

Figure 5. U.S. residential energy use (primary) per capita 1949-2003 .................................. 26

Figure 6. U.S. end-use, per-capita residential electricity consumption (site) 1978-1997 .......... 27

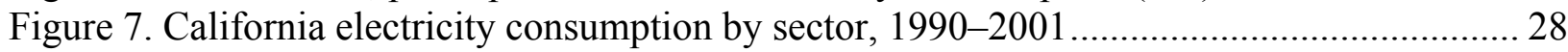

Figure 8. California per capita electricity consumption by sector, 1990-2001 ........................ 29

Figure 9. U.S. house size (floor area) mean and median 1950-2000 .................................... 29

Figure 10. Percent of new one-family houses 2,000 square feet or larger, West census

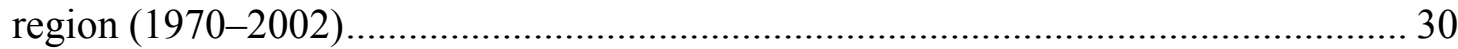

Figure 11. 1999 distribution of U.S. housing units by floor area .......................................... 31

Figure 12. 1999 total site energy consumption of U.S. housing units by floor area................... 32

Figure 13. 1999 energy consumption of U.S. houses per household by size of house.............. 32

Figure 14. U.S. residential energy use (site) per square foot by house size ............................ 33

Figure 15. U.S. 2001 residential energy use (site) per household member by house size.......... 33

Figure 16. U.S. 2001 total residential energy use (site) by household and housing type ........... 34

Figure 17. U.S. 2001 residential energy use (site) per floor area by housing type..................... 35

Figure 18. U.S. 2001 residential energy use per household member by housing type............... 35

\section{List of Tables}

Table 1. Residential end uses in California single-family homes (RASS columns), sorted by their contribution to residential sector electricity use

Table 2. A summary of cooling end uses in California residences served by California IOUs, based on the Residential Appliance Saturation Survey..... 


\begin{abstract}
The overall implementation of energy efficiency in the United States is not adequately aligned with the environmental benefits claimed for efficiency, because it does not consider absolute levels of energy use, pollutant emissions, or consumption. In some ways, promoting energy efficiency may even encourage consumption. A more effective basis for environmental policy could be achieved by recognizing the degree and nature of the synchronization between environmental objectives and efficiency. This research seeks to motivate and initiate exploration of alternative ways of defining efficiency or otherwise moderating energy use toward reaching environmental objectives, as applicable to residential electricity use in California. The report offers three main recommendations: (1) produce definitions of efficiency that better integrate absolute consumption, (2) attend to the deeper social messages of energy efficiency communications, and (3) develop a more critical perspective on benefits and limitations of energy efficiency for delivering environmental benefits. In keeping with the exploratory nature of this project, the report also identifies ten questions for further investigation.
\end{abstract}

Keywords: consumption, conservation, efficiency, energy use, energy policy, residential 


\section{Executive Summary}

\section{Introduction}

Current policy efforts to reduce global warming are inadequately served by their strong reliance on established definitions of energy efficiency. These definitions largely sidestep the environmental objective of reduced carbon dioxide $\left(\mathrm{CO}_{2}\right)$ emissions, since they fail to effectively consider absolute levels of energy use or the complexity of the relationship between efficiency and emissions. Insistence on efficiency as sufficiently "environmentally good" steers attention away from head-on recognition of environmental burdens caused by consumption itself, "the elephant in the living room." This lapse leads policy to overlook substantial technical and social potential. Rather than debating whether society can learn to consume less through morally-lead shifts in lifestyles, it may be possible to shift the definitions of efficiency from current forms to metrics and frameworks that better reflect absolute consumption and emissions. Doing so would open potential for more sharply-focused and effective approaches to greenhouse gas (GHG) emissions reductions.

Setting aside the possibilities of dramatic changes in how electricity is generated or how pollutants produced during electricity generation are controlled, the fundamental environmental problem is consumption of goods or services, rather than the efficiency with which these things are consumed. The U.S. trend towards bigger houses, for example, with more appliances and energy services, more space, more things that are always on, and the more disposable nature of all of it, represents an increase in material consumption. Although nominal efficiency of homes and appliances has increased substantially over the past thirty years, U.S. energy consumption per capita has also increased, as have the material requirements of "normal" living. There is no conflict between the increase in consumption and the increase in efficiency, but instead a potential conflict between the positive relationship between efficiency and consumption, on the one hand, and seeing efficiency as categorically good for the environment, on the other.

\section{Purpose}

The project was designed to examine relations between energy efficiency and energy consumption, and to explore unintended consequences that may result from using a toonarrow a concept of energy efficiency as the basis for policies intended to reduce energy consumption and carbon emissions. Focusing on residential sector electricity use, the report discusses possible alternative frameworks that may be better able to deliver carbon emissions reductions. In keeping with the exploratory nature of this project, research directions and needs are emphasized. Rather than forcing this research into a technical argument traditional for energy policy research, the emphasis is on drawing out conceptual shifts that should take place before technical and policy changes can take place. 


\section{Project Objectives}

The objectives of this project were to: (1) review limitations of current definitions of energy efficiency as tools for reducing environmental damage, (2) identify alternative constructs for describing environmental consequences of energy use, and (3) suggest ways to begin to bring these perspectives to fruition and make them suitable for policy, as applicable to residential electricity use in California.

\section{Project Outcomes}

This project reviewed existing definitions of energy efficiency as tools for reducing environmental damage and identified alternative constructs for describing environmental consequences of energy use. The report includes recommendations for further exploring these perspectives, to construct a new definition of energy efficiency that incorporates the alternative constructs into policy.

\section{Conclusions}

The fundamental environmental problem addressed in this report is one of the relationship between energy efficiency and consumption. The trend toward bigger houses, with more appliances and energy services, represents an increase in material consumption and a significant percentage of the state's electricity used to heat, cool, and operate them. The post-Energy Crisis, post-conservation, rally for energy efficiency has led to significant improvements in the nominal efficiency of homes and appliances in the United States. At the same time, U.S. energy consumption per capita has increased in a way that conventional definitions of efficiency have not been able to adequately capture.

Energy efficiency currently enjoys an environmental halo. Efficiency policy, however, is not sufficiently oriented to tracking consumption reduction, or more precisely, environmental damage due to consumption, to support such a reputation overall. At core, efficiency measures only relative consumption - and that at a disaggregate level, rather than one indexing total consumption or total environmental damage. This sometimes works as an environmental strategy, but sometimes it does not. Promoting the most energy-efficient products and services may at times inadvertently promote an increased use of resources overall. In any case, reliance on simple efficiency deflects attention away from facing the environmental impacts of consumption, rather than facing these impacts head-on.

Energy conservation is sometimes proposed as a solution, but the prospects for conservation as policy strategy are low. One promising option is to stay within the framework of efficiency, which is relatively viable politically, but to orient definitions of efficiency to better reflect consumption and environmental damage. This shift—a shift toward complexity - would have to occur on both technical and institutional fronts. There are formidable difficulties to achieving this shift, ranging from the ideological nature of efficiency, to the sociopolitical context in which efficiency policies, and environmentalism in general, take their form. However, such a strategy also offers a renewed set of opportunities for technological development and for social and policy creativity, on the basis of which incremental progress can almost certainly be made. 


\section{Recommendations}

The study makes the following recommendations:

- Consider integrating absolute consumption into technical and political definitions of efficiency. Depending on the end use, a variety of approaches should be considered to better track absolute consumption, rather than relative notions of consumption. These approaches include: (a) designing increasingly stringent energy efficiency requirements for larger goods; (b) placing absolute limits on consumption allowed for a particular good to be promoted as "efficient," and (c) making comparisons across a broader range of technologies and practices, rather than focusing on a specific end use (e.g., "cooling" as a category, rather than central air conditioning). The political and technical definitions should complement each other.

- Attend to the social messages of energy efficiency communications. If environmental protection is the goal of energy efficiency, focusing only on narrow definitions of relative energy savings diverts attention and effort away from more important environmental consequences of consumption.

- Broaden the definition of "environment" in stating the costs of energy use and the benefits of energy efficiency. Environmental damages resulting from energy consumption, such as direct pollution from electricity generation and damages resulting from the production of energy-using devices, should be considered along with carbon emissions when estimating damages from energy consumption. Identifying and better quantifying these environmental damages provides a basis for addressing them.

- Make sure the information given to consumers is good and fair. Providing simple advice to consumers to motivate them to invest in energy efficiency may be ill-founded, stated over-precisely or without sufficient qualifying conditions, or otherwise misleading, A critical review of industry practices and traditions for providing energy advice or savings claims is in order. A process for ensuring fact-checking could help alleviate these problems. Understanding the questions consumers actually have about energy use in the home, and directing efforts more closely to those questions, may be more effective than reproducing lists of energy-efficiency tips.

- Pay more attention to data, data quality, uncertainty, and trends. A comprehensive assessment of data availability, data needs, and the potential value (e.g., in advancing scientific knowledge or answering policy questions) of improvements in the data inventory would be of great use. Raising awareness about uncertainty, and guidelines for how it might be reported and treated, would also be valuable. 
- Develop a more open, critical, perspective on the benefits and limitations of energy policy and the assumptions on which they are based. With respect to addressing environmental quality, the fundamental dilemma of U.S. energy efficiency policy is that of moderating consumption while convincingly supporting economic growth. To achieve better success, conflicts between gross domestic product and environmental protection need to be openly discussed, rather than idealistically argued away; evaluations need to seek better ways to recognize and build from failures, uncertainties and assumptions need to be better identified and acknowledged, and the field needs to develop an ability to broaden the terms of discussion and debate.

The report lists a number of research topics that could address the issues above.

\section{Benefits to California}

In California and elsewhere, several public benefits could result from this work. To the extent that it can raise awareness of distinctions between increased efficiency and reduced consumption or reduced environmental damages, it may help change the basis of environmentally oriented efficiency measurement. If codes, technical standards, and marketing campaigns could better reflect consumption, they could create downward pressure on the size of houses or appliances, and how energy services are produced. Depending on their form, consumption-oriented policies could stimulate extra boosts of efficiency for larger houses or appliances, encouraging innovative technical approaches to enter the market, and could encourage lower-consuming social systems overall. Similar arguments hold for various energy services within houses. Ultimately, efficiency definitions and policy frameworks that better reflect absolute consumption can lead to substitution of lower-consuming services and increased technical innovation directed to meeting these new, consumption-oriented, metrics, achieved mutually through technical and social systems. Most importantly, it will help efficiency and environmentally oriented energy policy better and more accurately serve the environment, rather than encouraging more consumption. 


\subsection{Introduction}

Since the mid-1980s, energy efficiency has gained standing as a nearly unquestioned environmental good in the energy and environmental policy community. Energy efficiency has become one of the leading policy responses for addressing global warming. According to accounts told within the efficiency field, efficiency has been a great success in the United States, having delivered avoidance of hundreds of millions of metric tons of carbon dioxide $\left(\mathrm{CO}_{2}\right)$ emissions each year. At the same time, despite this avoidance, carbon emissions in the United States have been increasing, overall and per capita. On a macro scale, energy efficiency has not led to a society that is environmentally less damaging than before. On a micro scale, energy-efficient things in general are not less environmentally damaging than their inefficient counterparts: a big efficient house is not environmentally better than a small less-efficient one, a big-screen projection TV, however wonderful, is not environmentally better than a 19" tube-based machine, and so on. Analyses that aimed to calculate savings from efficiency for these examples would use different baselines than the ones offered here; they would track the theoretical reductions of energy consumption or emissions that energy efficiency offers relative to less-efficient versions of the same size or type of system. The baselines used in calculating savings often hide critical questions concerning the environmental pedigree of efficiency.

In view of environmental claims being made for energy efficiency, there is something more that needs to be openly researched and debated, if not for energy and environmental policy to succeed in some notion of sustainability, then to come to terms of what energy efficiency is accomplishing. The need for these discussions is not obviated by defending efficiency on its own terms, such as justifying mixed progress by citing increased standards of living or economic well-being, appealing to reasonable expectations, or arguing relative successes. ${ }^{l}$ The problems must be better understood before jumping to defenses or proposals for solutions. This report tries to help develop this understanding by providing motivation, framework, citations, and some exploratory analyses.

The specific problem addressed here is that of the relationship between energy efficiency and environmental damage, with a California focus. From the start, it should be made clear what the report does not do. First, it does not argue that energy efficiency is categorically unjustified or otherwise bad, nor does it try to prove, in general, that energy efficiency causes energy consumption to grow. As noted below, many economists do argue that efficiency causes economic or consumption growth. ${ }^{2}$ The authors do not disagree, but this study's argument is not framed in economics. In any case, energy efficiency may act differently in different cases, contexts, countries, and times. What was true in the 1970s in the United States may not be true there now, nor true in Kazakhstan

\footnotetext{
${ }^{1}$ Both increased "standards of living" and "economic well-being" are almost inevitably indirectly or directly defined, in an economic arena, by increased consumption, and vice versa.

${ }^{2}$ In contrast, it is often claimed that energy efficiency decouples energy consumption from economic growth, so that energy efficiency is a "win-win" strategy. The question remains how well the two can be decoupled, and how well economic growth can be had without increasing environmental costs.
} 
or France. Second, this report does not catalog examples where efficiency has worked well. This work is about cracks in what efficiency, in its current manifestations, is presumed to deliver. Energy efficiency can be good for the environment, but this is not universally true. Third, this report does not make moral arguments against consumption. Rather, it argues that if energy policy is to continue claiming environmental benefits in the way it has in the past, it needs to address consumption head on, and to reexamine how energy efficiency impacts consumption and environment. Can efficiency, as rendered by our current political/economic/sociological/business traditions, be shifted to truly reduce environmental impacts? Or is efficiency, through its basic ideology if not its implementation, doomed to miss consumption? Fourth, the report does not provide a detailed list of recommended policy instruments, neither on the technical or the economic side (e.g., the authors do not argue that carbon taxes or other internalization instruments are the ultimate solution). ${ }^{3}$ While acknowledging the importance of supply-side strategies for effective environmental policy, this report does not pursue supply-side solutions in any detail, though it offers suggestions as to how they might be better integrated with efficiency approaches.

\subsection{Background: The Dilemma of Using Efficiency as a Policy Tool for Reducing Carbon Emissions}

The problem at hand: What are the observed relationships between energy efficiency policy and reduced energy consumption and carbon emissions? Over the past few decades in the United States, increasing energy efficiency at the micro level appears to have produced large relative savings. This strategy has several advantages, but the bottom line for the environment rests predominantly on totals - that is, on absolute levels of emissions and total resource consumption. The Intergovernmental Panel on Climate Change (IPCC) estimates that GHG emissions need to be reduced by $50 \%$ to stabilize atmospheric concentrations of carbon dioxide (IPCC 2001). Even as the emerging temper of GHG-control efforts appears to be to slowing the rate of damage, rather than to avoid or repair it, the ability of efficiency in delivering these benefits should be reevaluated, rather than taken as a matter of faith.

The government of California has implemented many efficiency policies oriented to carbon emissions reduction and to environmental protection, supplementing and typically exceeding national policies affecting the state. Nationwide, energy consumption and carbon emissions continue to grow, overall and per capita (EIA 2003, 2004a). The recent California record is better than the U.S. average in terms of recent consumption growththat is, it has increased less. Electricity consumption has increased over the past 20 years, ${ }^{4}$ though per capita consumption has been mostly stable from 1990-2001. These national increases occurred despite large relative energy savings that have been attributed to energy efficiency. Similar patterns of increased consumption are seen in Europe (EEA

\footnotetext{
${ }^{3}$ Economic efficiency, the target of internalization instruments, seems to suffer from the same fundamental problems as energy efficiency insofar as reducing consumption is concerned.

${ }^{4}$ Between 1980 and 1999, residential electricity consumption increased at a rate of 2.0\% per year (from 52 to 78 terawatt-hours/year (TWh/yr)), while population increased at a rate of $1.8 \%$ per year (from 23.8 to 33.9 million) and the number of housing units increased at a rate of only $1.4 \%$ per year (from 9.3 to 12.2 million) (Brown and Koomey 2003).
} 
2001a). ${ }^{5}$ It is impossible to say definitively what efficiency's role has been in changing these patterns; any precise answer depends heavily on subjective assumptions. Emissions growth in many developing countries has been dramatic, due to population growth and a heavy increase in the accoutrements of Western living, even while remaining at levels considerably lower than the U.S. per capita average. No doubt there will be substantial technological progress in various realms, but there is no reason to expect the emissions reductions, or other types of environmental benefits, to overcome the consumption increase. In the short run, it may be worse: for older end uses long governed by energy efficiency policy, it becomes harder to make marginal efficiency improvements. New end uses proliferate, but prove more difficult to address through traditional policy means.

Historically, energy efficiency has been used as a policy tool for a variety of different purposes. These include economic competitiveness, resource conservation, energy savings during times of crisis, and cost savings. Generally, efficiency has been a means of increasing productivity. It is only since the mid-1990s that its potential for environmental protection has predominated, though its performance in this regard is often taken for granted. The legacy of efficiency's previous purposes are reflected in the practices and traditions of the energy efficiency field. Can something oriented to increasing productivity - which, arguably, usually entails increasing production - also reduce consumption? ${ }^{6}$ The apparent discord points to a central tension in efficiency itself: efficiency is supposed to help society consume better (as economists assume) as well as to consume less (as environmentalists assume). Efficiency does not speak to ends (Bromley 1990), and thus it tells nothing about what is consumed — a naturally appealing characteristic insofar as economic growth is concerned. Even as we suggest ways that efficiency might be recast to better capture consumption, its fundamental character, or its inevitable implementation in the context of present-day United States, may place serious limits on what efficiency can do. A central example in this study is a trend towards larger houses, especially the highly visible case of so-called "monster homes," which raise questions about what might be called energy efficient when efficiency is justified for environmental purposes.

The energy policy research community, as a group, does not have a reputation of being self-critical, nor has energy efficiency policy been subject to much critique from outside. Those who do critique tend to be viewed politically, as enemies of efficiency or efficiency funding. However, there have been widespread intimations that things are not what they should be (e.g., Bromley 1990; Herring 1998 and 2006; Moezzi 1998; Nader 1981; Rudin 1992 and 2000; Shove 2003; Wilhite and Nørgård 2004). Visible ironies, cracks in the system, become evident. One is the growing size of California residences, combined with the fact that very large houses can readily be counted - even showcasedas "efficient and environmental," while they are destined to consume more energy and resources than more modest houses. The case of refrigerators may be another crack: despite dramatic increases in efficiency requirements over the past 20 years, with the

\footnotetext{
${ }^{5}$ According to EEA 2001b, electricity consumption per household in the European Union 15 (EU15) countries increased 32\% between 1985 and 1998 (Table 2 in that report).

${ }^{6}$ This presumes that consumption is proportional to environmental damage, which is roughly true, short of radical changes in what consumption entails.
} 
uncertainties of the data record, total energy consumption by refrigerators is about five times what it was in the late 1950s (Deumling 2004). The "largest flat-screen plasma TVs" can earn an Energy Star ${ }^{\circledR}$ rating, indicating the purchaser's contribution to preventing global warming, shifting the environmental focus to the relatively small contribution of energy efficiency improvement offered by low-power standby mode, away from the overall environmental consequences of the choice. ${ }^{7}$ Promoting energy efficiency need not entail condemning consumption. However, encouraging consumption runs counter to environmental objectives used to justify efficiency. These examples are not specific to California. However, California is a world-leader in environmental policy, encompasses a creative populace, commands a great amount of relevant scientific expertise, and uses a tremendous amount of energy, and is thus well-positioned to lead the way.

In considering California's electricity consumption trends, Brown and Koomey (2003) write, "[A]t the sectoral level, electricity intensity... was declining at a rate of $0.5-3 \%$ per year. This supports the hypothesis that gains in California electricity efficiency were more than offset by increased population and economic activity" (emphasis added). This is an important point, to look at overall progress rather than a subset of modeled trends attributable to increased efficiency. However, this orientation also defends the progress of efficiency, and renders economic growth as a largely independent factor. Whether or not efficiency in electricity end use promotes economic growth, "more of the same" is not a convincing solution if energy policy is to deliver absolute savings. Nor is there an innate conflict between large energy savings and the substantial consumption increase: savings are estimated relative to a baseline of what would have happened otherwise on an end-use by end-use basis. End uses are uncontrolled, and "what would have happened otherwise" is, by definition, a hypothetical outcome rather than a real one. There seems to be a general recognition among those in the field that technically based estimates of savings are often optimistic in nature. Much of the definitional problem in how to account for the impact of energy efficiency lies in an under-examined notion of what is meant by "savings." While each year reports from the efficiency community claim or promise substantial reductions in carbon emissions, the constructed baseline is often one of substantial projected growth based on current end uses. In the meantime, society's ability to think of new ways to use energy grows even as technical efficiency increases (Oreszczyn 2004). The more energy services demanded, the more the potential to save. Energy efficiency itself often becomes a good to be "consumed."

Economists have long talked about "rebound" or the "take-back effect," which is the argument that energy efficiency lowers the price of energy services and, thereby, makes them, and the use of energy, more affordable (Herring 1998, 2006). It is often argued that this rebound effect is small, a few percent and certainly not greater than $20 \%$, though others argue it is greater-100\% for example (Herring 2006). Within economics, the rebound effect is a specific notion, calculable within a particular framework which assumes that increased consumption is a consequence of shifting capital. As explained

\footnotetext{
${ }^{7}$ From the Energy Star website, "Buy Products that Make a Difference." www.energystar.gov/index.cfm?fuseaction=find_a product.showProductGroup\&pgw code $=T V$ (accessed June 2005).
} 
below, this report's argument on efficiency and consumption are distinct from the rebound discussion.

In defending energy efficiency's environmental benefits in the face of increased energy consumption, there are three frequent reactions from the energy policy community:

1. That energy efficiency is a great improvement over what would have happened otherwise, by treating the calculated end-use savings as absolute energy savings. Within this interpretation, energy efficiency by definition has delivered substantial savings.

2. That more efficiency would solve the problem, even if past efficiency efforts have not.

3. To acknowledge the limitations in what energy efficiency, or energy efficiency as implemented through policies, has done or perhaps could do.

The first reaction is the most common, but does not escape from the nearly tautological nature of the savings claimed: if you claim that savings are the difference between what would have happened and what did happen, there are always going to be savings - the framework defines a reality that guarantees this. The second response is really an extension of the first - that we need more of the hypothetical savings from our assumed baseline. There is a need for a broader perspective if the goal is to effect absolute environmental quality, and that the third response is the most productive. One danger is that the examination of the "limits" to energy efficiency often leads to the conclusion that doing better requires dramatic changes in moral values and behavior, which are presumed "off limits" for political reasons, so that energy efficiency programs should persevere to make the world as technically efficient as possible, without addressing larger issues. This polarization between technology and behavior often leads to stalemate, one side emphasizing a basically moral imperative to reduce energy consumption through customer behavior, and another side arguing a technological imperative for society to adopt more energy-efficient technology. But efficiency is, after all, invented by people, and is subject to all the social forces and norms that govern its development and dissemination. Thus, the problem is far more interrelated, as this discussion will try to show. Imbedded amongst these technical-moral arguments is a clear conflict between the political drive to increase gross domestic product (GDP) and an international environmental argument that the United States already consumes a disproportionate share of the world's resources. The challenge is to improve the environmental performance of efficiency, or to be more honest about its limitations, or both.

\subsection{Project Objectives}

The project was designed to examine relations between energy efficiency and energy consumption, and to explore unintended consequences that may result from using energy efficiency, as conventionally defined, as the basis for policies intended to reduce energy consumption and carbon emissions. The approach combines literature review, case studies, data analysis, and social scientific critique. This report discusses possible alternative frameworks that may be better able to deliver carbon emissions reductions. In keeping with the exploratory nature of this project, research directions and needs are 
emphasized. Rather than forcing this research into a more technical framework traditional for energy policy research, one that would produce quantitative estimates and procedural recommendations, the authors try to draw out some of the conceptual revisions that they believe are necessary before technical and policy changes can take place.

\subsection{Report Organization}

This report is organized into the following sections: 1.0 Introduction, which provides background information and identifies the principal questions for the study; 2.0 Approach, which describes the framework and methods for the research; 3.0 Findings, which reports the findings from the literature survey and the three case studies; 4.0 Policy Recommendations, preliminary suggestions for how policy makers can use the findings; and 5.0 Conclusions, summary points and suggestions for further research in this area. 


\subsection{Approach}

After reviewing the literature and state of knowledge on residential energy efficiency and consumption, focusing on issues pertinent to electricity use in California residences, several case studies were investigated, covering a variety of residential electricityconsuming services, including single-family (SF) dwellings themselves. Although data on rated efficiency and rated or measured energy consumption was sought, for the most part, the publicly available data was, from a statistical standpoint, often inherently inconclusive for this study's questions. The authors had originally hoped that it would be possible to concretely suggest alternative metrics and frameworks that combine the traditional notion of efficiency with increased emphasis on the control of absolute consumption and emissions, such as could serve as the basis for designing policies that would promote reductions in residential electricity use. However, not only were data inadequate, but just as important, the efficiency definitions specified in policy are hardly "simple." The efficiency definitions are often intricate combinations of categories, exceptions, and limits, test procedures, and measurement conditions. Specific recommendations would risk being so stylized or naïve that they would miss much of what is important (for example, "loopholes" for consumption). Furthermore, there are the complex and largely unknown relationships between policy specifications and market availability: for example, the data on what energy efficiency measures are sold and how they are operated are very limited. Consequently, the study was oriented toward producing a more general set of questions and recommendations, drawn from its analyses and from the reviewed literature, supported by technical analysis where data were available. One of the historic stumbling blocks of this field has been the failure to look at the big picture, while focusing on the details of specific end uses. Thus, this analysis starts with, and often hearkens back to, the big picture.

\subsection{Framing the Problem}

Seven considerations are central to the relationship between residential energy efficiency policy and the environmental protection: (1) consumption, (2) environmental effects of energy consumption, (3) the residential sector, (4) definitions of energy efficiency, (5) limitations of existing data, (6) potential and limitations of policy, and (7) the social messages of efficiency marketing. In the everyday business of energy efficiency, these issues often seem to stand outside the problem, appearing obvious or fixed, relevant to another realm. However, they have important bearing on what "the problem" actually is and how it is addressed.

The following equation provides a schematic representation of the relationship between energy efficiency and carbon emissions:

\section{Total Carbon Emissions $=(\text { Energy Efficiency of a device })^{-1} *$ Number of devices * Amount of service demanded from each device * Carbon emissions per unit of energy used}

For total carbon emissions from residential refrigerators in California, for example, one produces, for each refrigerator in service, the product of its energy intensity (reciprocal of 
efficiency) times the amount it is used (e.g., 8760 hours per year), which gives energy use, which is then scaled by a carbon emissions factor reflecting properties of the electricity used. This total is the sum of this product over all refrigerators in California. The point of this exercise is to emphasize that efficiency is just one element of the equation, and in no sense the dominant one. Any of the three other elements on the right side of the equation can change, and each in a variety of ways. Savings from efficiency are usually calculated by holding all these other elements fixed: on the one hand, this appears to isolate efficiency's contribution; on the other hand, it fails to connect efficiency to the total environmental picture.

Instead, history shows a strong tendency for the number of products and the services demanded of them to increase. Because energy efficiency does not reflect number of devices used, demand for increased service, increase in population, and other such factors, it cannot trace total consumption or changes to consumption. Moreover, efficiency, whether in its technical nature or in the larger social context, may sometimes cause, or is at least often complicit with, increases in the other factors and, therefore, in leading to increased consumption. Through this mechanism, efficiency can thus counter or even outweigh its "internal" capability of reducing consumption. This ambiguity in the definition of energy efficiency is of central concern in this study's analyses.

\subsubsection{Rebound Effect}

This study's arguments do not reduce to the "rebound effect." Since there is overlapping territory, this section summarizes the literature on rebound effect and explains why this study's arguments are distinct. The "rebound effect," sometimes called the "take-back" or "snap-back effect," stands as one of the most popular topics in energy efficiency since the early 1990s. It is one way of addressing what efficiency does, and the most evident bone of contention between those who say efficiency reduces energy use, etc., and those who say it does not. In popular usage, rebound refers to cases where consumption reductions due to an intervention are less than what were expected, because of the effect of the intervention itself. The economic usage of the term is more precise. It is often separated into three types: direct effects, indirect effects, and general equilibrium effects. The direct effect refers to increased use of energy services induced by the reduced cost of energy services resulting from increased efficiency. The indirect rebound effect refers to increased consumption occurring because efficiency causes the resulting disposable income to rise. The general equilibrium effect refers to macroeconomic adjustments of supply and demand to these changes (Herring 2006).

The rebound effect is often estimated to be small, ranging from a few percent up to $20 \%$ (Herring 2006); whereby the battle over rebound seems to reduce, for some, to a matter of adjusting savings estimates downwards by a few percent, an amount often trivial relative to the overall statistical uncertainty of the savings estimates. In any case, this would not solve the problem. These estimates of "a few percent take-back" concern only the direct rebound effect. Herring $(1998,2006)$, who provides excellent summaries of the debate, remarks: 
[A] wide range of energy economists ... have all maintained that increased energy efficiency at the microeconomic level while leading to a reduction of energy use at this level, leads not to a reduction, but instead to an increase in energy use, at the national, or macroeconomic level. Their arguments have been supported by the historical record for most of this century, of increasing levels of both energy efficiency and energy consumption. (Herring 2006)

We have efficiency reducing consumption at the same time it is increasing consumption, depending on one's perspective. The complication here concerns causality. The rebound effect attributes increases in energy consumption, or decreases in savings, to efficiency itself, while those who argue that the rebound effect is non-existent or small consider increases in consumption to have occurred largely independently of efficiency.

Given its imprecise use in the energy literature, compared to a precise meaning in economics, the notion of rebound is confusing. The reason the lines of the rebound argument are not pursued in this report, however, is not to avoid this confusion. In reflecting on the idea of economic externalities, sociologist Michel Callon (1998, 256) writes: "economists - and it is one of their great virtues - demonstrate... an obstinate desire to define the conditions in which actions become calculable, and to think up devices that will encourage such conditions to emerge." However, the real world is always overflowing these boundaries, he argues; it is up to the social sciences to focus on "the omnipresence of these overflows, on their usefulness, [and] also on the cost of the actions intended to (partially) contain them" (Callon 1998, 256). By arguing about rebound, one restricts oneself to what can be proved in economics, which is not only data-limited, but, even more important, invokes many hidden assumptions about the way the world works. These assumptions severely limit what can be seen or admitted. As useful as economics is, it is too restrictive to serve as the only perspective from which to assess something as complicated, and social, as consumption.

\subsubsection{Consumption}

In the equation in Section 2.1, consumption is the product of the number of devices and the amount of services demanded from these devices. Thus, consumption increases as the result of the increasing numbers of devices driven partly by increasing population. In general, consumption has increased faster than population: people find more types and higher levels of energy services to consume, whether seen as being driven by personal choice or as a matter of various other (e.g., social, psychological, market, technical) pressures. Energy policy sees consumption almost entirely as the former, a matter of a series of considered decision-making by "consumers," usually at the point of purchase and sometimes concerning choices about use. Thus, the human side of consumption is reduced to addressing questions of the efficiency of the devices people will purchase. That is, it is only efficiency (not the size, the type, nor the reasons for buying) that is the leverage point. Here is where most of the "market barriers" literature focuses, portraying the choice for more energy-efficient products as something that can and should be facilitated by offering information, direct financial benefits, or supply-paths that make it easier and more compelling to buy energy-efficiency. Information can certainly be 
influential, but there is good reason to be skeptical of how far providing information to consumers can go (Shove 1998, 2003). Moreover, "consumers" is a marketing term, and one that reflects primary interest in sales. People are far more than consumers. Whatever such efforts to influence consumer choice between this or that model can do, the choice for or against efficiency at any purchase point is but a small part of the entire consumption question. Efficiency promotion can become, in effect, promotion to buy. Nørgård $(2005,2)$ comments: "Politicians, at best see energy efficiency, as well as solutions to other environmental problems, as an arena for new economic activities." To the extent that this is true, can efficiency, or other potential solutions to carbon emissions reductions, be rendered in any other way?

Patterns of consumption follow from efforts to provide and sustain what people take to be normal services, providing "comfort" for example, with expectations of these services changing over time (Shove 2003; Chappells and Shove 2004).Some environment-driven efforts try to create a strongly moral obligation for consumers to consume less or consume better, whether of the "easy things you can do to save the earth" variety or of the larger-scale "live simply" type. Both of these types of efforts try to change what is considered normal behavior. These efforts may do as well as they can, but there is little reason to believe that they can result in any large-scale transformation, especially as they rest essentially on the personal "heroism" of individual consumers that exist within an economic and political system that is designed to increase consumption.

Part of the mechanism through which consumption increases is the design of appliances, equipment, and houses for maximum expected demand. For example, residential contractors generally size air conditioners to be considerably larger than required by manuals, as both a risk-averse and income-generating approach on the part of the contractor (Vieira et al. 1996). This practice combines with the normal engineering legacy in which technologies should be designed to withstand more than the normal maximum - even while the nature of the failure ("a bit too hot") is generally not very serious.

Houses may also be upsized by a similar combination of factors: contractors can make a larger profit on a larger house, which consumers can readily be convinced to buy (Baker 2004). Combined with the tendency for "spare" capacity to be filled (Shove 2003), this leads to the escalation of need or demand and generally, environmental damages. Ironically, the same upscaling of consumption has appeared in "green" markets as well. A noted green architect, describing his 4,000 square foot $\left(\mathrm{ft}^{2}\right)$ green house, said: "We're not in the business of telling people to be less bad... We're about $100 \%$ more good" (quoted in Baker 2004). The same article noted this tendency by observing: "Give Americans sustainable technology, and we'll supersize it beyond recognition" (Baker 2004). This study's argument does not require judging $4,000 \mathrm{ft}^{2}$ houses as morally bad, nor that Americans are bad or immoral because of this tendency toward upsizing; it does assume, however, that generally this upsizing has adverse effects on the environment. 


\subsubsection{The Environmental Effects of Energy Consumption}

Carbon emissions are virtually the only environmental indicator used in U.S. energy efficiency policy analysis, apart from energy consumption itself. Policies are generally framed around energy savings, from which carbon emissions reductions are calculated. From a logical standpoint-comments on practical aspects to come-there are remarkable flaws in this arrangement. First, to the extent that policies are meant to effect carbon emissions reductions, plans would be better indexed to carbon emissions themselves, a better basis for optimal allocation of program resources. ${ }^{8}$ Moreover, doing so could pave the way for better integrating supply choices into the program's environmental equation. Second, carbon emissions are but one of many environmental damages caused by electricity generation, along with emissions of particulates, nitrates, and sulfates into the atmosphere; ecological disruption caused by dams; and radioactive waste produced in the nuclear process. These vary with the sources and manner of consumption, and at the source level, are not proportional to carbon emissions. Research on environmental externalities of electricity production has produced a set of concepts and tools to estimate the environmental impacts of electricity production, from $\mathrm{CO}_{2}$ emissions (as well various other environmental and health damages, etc.) for a variety of generation sources (especially the ExternE project; see European Commission 2003). The ideal of environmental externalities estimation is to support the development of economic instruments by which society can internalize external costs.

Another option for characterizing environmental effects is the "footprint" perspective. The footprint is offered as a comprehensive measurement of environmental impacts of living, on a per-person or a per-group basis. Obviously, there are many technical questions about how these impacts might be measured or expressed, and various different software options for estimating footprint are available. ${ }^{9}$ These are generally directed to providing information to interested individuals, who are accordingly encouraged to reduce their footprint by making better environmental choices. The concept's utility in policy analysis and development is unclear.

There is thus considerable imprecision in energy efficiency's ability to moderate environmental effects or even to control carbon emissions. On a practical level, this imprecision would not be simple to overcome (one can hardly imagine, for example, stricter refrigerator standards for regions in which carbon emissions factors are high). However, one can imagine a policy framework that better integrates generation with electricity consumption, within which certain renewable energy technologies better compete, given their generally lower levels of environmental damages as compared to fossil fuel combustion.

\footnotetext{
${ }^{8}$ Policy analyses may often judge the efficacy of a program in terms of carbon emissions reductions, but generally after much of the variability in carbon emissions factors (carbon emissions per unit of energy or power) have been averaged out.

${ }^{9}$ For example, the "Ecological Footprint Analysis" from Redefining Progress (http://www.redefiningprogress.org/footprint/),
} 
Energy policy naturally focuses on direct energy consumption. However, any bit of energy consumption relies on some other type of consumption that enables the services provided by energy. The new refrigerator not only promises the usage of so many kilowatt-hours (kWh) to come, it is an assembly of metal and plastic and other materials that required energy to make and transport as well. So there are a number of environmental costs integrated into every transaction that are not counted in the efficiency equation. Although there are no policies in place to control overall consumption, campaigns to control particular types of consumption have been successful historically (Diamond and Moezzi 2004). Finally, it is worth noting that while this project addresses only electricity consumption, $84 \%$ of California residences use natural gas, which runs $68 \%$ of the main heating systems in California residences (EIA 1999), usage also resulting in GHG emissions. Nationwide, the contribution of electricity to GHG emissions has been increasing, relative to the contributions of direct natural gas and other fossil fuel combustion.

\subsubsection{The Residential Sector}

Residential sector energy consumption is conventionally defined as energy consumed directly within the home (e.g., EIA 2004b). This definition typically overlooks losses due to generation and transmission of electricity, which favors electricity over other fuels insofar as controlling absolute consumption is concerned. The conventional definition of residential sector also constrains how consumer behavior can be seen with respect to energy consumption. The energy impacts of the resident far transcend consumption that takes place within the home, such as the transportation implications of the home location and the indirect consumption associated with all that the resident acquires. Although indirect consumption is not readily amenable to policy decisions, it is a very important component of the environmental impacts and energy implications of consumer choices. Bin and Dowlatabadi (2005) argue that while only $27 \%$ of national energy consumption is consumed directly in households, an additional $57 \%$ is attributable to indirect consumption by households, a category that includes the embodied energy in the foods and materials used in the home and outside the home (e.g., cars).

The "footprint" concept is designed to encompass some of these considerations. Footprinting's ability to integrate both total consumption and consumption tradeoffs (e.g., "I'll drive an SUV, but only 6,000 miles a year, and I live in a small house") may be a nice complement to efficiency definitions, which, in general, integrate neither total consumption nor tradeoffs. It is unclear how this could be implemented in policy, however, and as noted above, the assumption that providing information on environmental footprint to consumers is sufficient to instigate much change is questionable. However, there may be appreciable potential here.

\subsubsection{Definition of Energy Efficiency}

The Energy Information Administration (EIA) characterizes energy efficiency as a "value-based, philosophical concept" (EIA 1995). In practice, however, it appears to be a technical and objective term - one which requires a great deal of work in defining the 
context under which these objective measures might be defined. Witness the complex and controversial processes of defining energy efficiency for various programs and policies, such as the National Appliance Energy Conservation Act (NAECA) standards process for U.S. Department of Energy (DOE), or in the Energy Star program ${ }^{10}$ While efficiency itself is highly valued economically and, we suggest, in American morally, efficiency definitions are usually treated as value-free and objective, as if they were grounded in thermodynamics. However, the policy process entails a fair amount of debate on the ways in which these definitions are made and the precise levels that are required. The meaning of energy efficiency is based on definitions of "services" provided, and the definitions of services vary widely. Therefore, it is very hard to compare different uses of the term energy efficiency. As Herring (2006) warns, "Measuring energy efficiency, particularly on a macro scale, is fraught with methodological problems and is very hard to measure over time, and between countries and sectors." The technical nature of energy efficiency definitions at first glance appears to reduce technology and consumption into purely technical matters. However, the choices behind the development and use of technical devices and reasons for energy consumption are eminently social, even if at certain fundamental levels they address physical facts and needs.

\subsubsection{Data Availability, Quality and Uncertainty}

Limited data availability hinders energy policy research. Energy consumption in the real world is everywhere, and energy consumption is complex, abstract, and difficult to describe. Measured data on end use consumption, and its variability, is particularly lacking. This situation makes it difficult to collect the types of data that ideally would make it possible to make comprehensive analyses. In our judgment, the data available and the techniques used for analysis often only poorly support the tasks undertaken, especially insofar as the uncertainties are rarely admitted. While totals for consumption may be well known, what is known of end use consumption in residences, for example, is typically triangulated through a number of sources: laboratory measurements, modelbased estimates, surveys, information on total production and consumption, and, to a limited extent, in-use metering. As shown in the examples below, there is even disagreement as to the direction of some basic energy consumption trends. More data are available, but they are proprietary. Furthermore, data are often aggregated, rather than revealing the diversity or distributional characteristics so important to understanding realworld problems and policy-effectiveness. Though a great deal of energy data are collected, it is often difficult to fund data collection efforts that are sufficiently detailed

\footnotetext{
${ }^{10}$ Energy Star is a joint program of the U.S. Department of Energy and the U.S. Environmental Protection Agency (EPA), "helping businesses and consumers to protect the environment through superior energy efficiency" (www.energystar.gov/index.cfm?c=about.ab index). McWhinney et al. (2005) describe the process of efficiency specification for several Energy Star product programs. The Energy Star program is generally designed to complement DOE standards, promoting higher efficiency than the DOE NAECA standards for goods covered by standards, and promoting efficiency in realms not covered by standards as well. While the NAECA standards program highlights economic benefits, the Energy Star program foregrounds environmental benefits as long as they come along with economic benefits. The "profitability" requirement of these two major programs leads to an important challenge for environmentalism regarding the performance of environmental concerns when they are essentially linked to increased profit or economic growth (Meier 2003).
} 
to scientifically support policy. In an Excel workbook, low-quality data look the same as high-quality data, so concerns about data quality are often obscured. Also, models generally provide more manageable results than "measured" data, and in a shorter time frame. Since policies, in the end, seem to demand definitive numbers, the research side is pressured to comply with analyses with limited data sets, or else run the risk of not being able to do the study at all. We do not need perfect answers, but we need to have a better of idea of how good our answers are, relative to the decisions to be made based on them. From a scientific viewpoint, uncertainties should be reported quantitatively as much as possible, but this in itself is challenging from a research angle, and answers with big uncertainty ranges are politically problematic, because they may not lead to clear policy alternatives.

In any case, uncertainty in the data rarely are reported quantitatively. Even when they are reported, analysts often end up using "central estimates" as working truth, and caveats are readily forgotten. As an example, the EIA's Residential Energy Consumption Survey (RECS) - the main source of information on energy use in U.S. residences-reports statistical quality indicators for their data (e.g., EIA 2001). The EIA is generally careful about noting the presence or absence of statistical significance. However, the resulting end use estimates are expected to be rough (if not on average, then certainly for individual houses or subsections), and this roughness will be especially pronounced for highly variable end uses, like air conditioning (EIA 1999). In summary, there is a tendency to focus on theory-based estimates and to take these theory-based estimates as truth, usually without adequately expressing uncertainties or acknowledging their impact on research conclusions.

To illustrate another dimension of the data situation, consider one of the most basic of questions in residential energy consumption. EIA reports that there has been no statistically significant change in total U.S. residential energy consumption between the first RECS survey in 1978 and the most recent one in 2001 (Laurence 2004). ${ }^{11}$ Given that population increased $26 \%$ over the same period, this appears to be evidence of phenomenal success for residential energy efficiency. ${ }^{12}$ However, data from EIA's Annual Energy Outlook (EIA 2004a) indicate that U.S. residential energy consumption was $25 \%$ higher in 2001 then in 1978 - and, incidentally, 38\% higher than in $1974 .^{13}$ Analysts and policymakers are faced with two dramatically different results on residential energy consumption, both offered by EIA: one suggests no change in residential energy consumption, and the other suggests a $25 \%$ increase over the same period. The principle reason for this difference appears to be that the first analysis (Laurence 2004) is based on site energy consumption, and the latter on total (source) energy consumption. "Site" energy refers to energy consumed at the point of use, while "source" energy refers to the

\footnotetext{
${ }^{11}$ The point estimate for 2001 is $2 \%$ higher than that for 1978 - a difference which is not statistically significant, i.e., the survey data give no basis for claiming a difference.

${ }^{12}$ The number of housing units increased by $40 \%$ over the same period (Laurence 2004).

${ }^{13}$ Table 2.1b, Residential Energy Consumption 1949-2003, Column V ("Total"); available at http://www.eia.doe.gov/emeu/aer/txt/stb0201b.xls. Technically, the RECS consumption data are for the year ending one year prior to the date of the survey (e.g., 2001 RECS corresponds to 1999 consumption). However, for clarity and tradition, this report uses the survey year, e.g., 1978 and 2001.
} 
energy consumed at the power plant. ${ }^{14}$ While there is essentially no difference between site and source energy consumption for natural gas and oil, source energy for electricity is about three times that of site energy consumption (the exact figure depends on the fuel generation mix used to produce electricity at a given plant). Over the 24 years compared in the Laurence analysis, the contribution of electricity to total residential energy use has increased dramatically, as contributions of natural gas and oil have decreased. However, the first comparison utilizes site energy in its comparisons, thus hiding increases in electricity consumption. While both analyses may be accurate, in practice their different meanings are readily forgotten, and thus one could readily choose one or the other despite their very different results. ${ }^{15}$ In summary, despite the fact that relatively complete data on trends are available, the basic record on trends in total residential energy consumption is muddy. ${ }^{16}$ In understanding and improving the effectiveness of energy policy, theoretical and "approximate" estimates of energy consumption and savings may be major hindrances to judging success.

\subsubsection{The Potential and Limitations of Policy}

This project invokes fundamental questions about what energy policy can and should do for the environment. Judging from current discourse, the apparent answer is that policy should aim to improve technological infrastructure so long as doing so is societally costeffective. Even if this is done well, this addresses a relatively small part of the environmental impacts of energy consumption and of consumption in general. The scale of improvements falls far from matching, for example, the targets for carbon reduction identified by the IPCC in order to stabilize atmospheric concentrations of GHGs. On a visible level, it falls short of stemming the visible increase in consumption "everywhere," from housing developments packed with big houses, to magazine articles on the exploding market economy in China, and to more and bigger cars on the road. Yet the environmental field seems only beginning to openly recognize a shift from a saving-theearth idealism to the flexibly modest goal of slowing the rate of damage. From the standpoint of marketing environmental protection, slowing the rate of damage in light of all these visible changes is not an inspiring goal; it is even less so when the damage is perceived as occurring generations in the future or to parties elsewhere (since the most severe damage of global climate change is expected to occur in the southern hemisphere). Market-based efficiency programs routinely promote energy efficiency as "saving the earth." From the perspective of marginal improvements in the energy efficiency of "predestined" individual purchases, this claim can be seen as relatively true. However,

\footnotetext{
${ }^{14}$ See EIA's discussion at http://www.eia.doe.gov/emeu/mecs/mecs94/ei/elec.html.

${ }^{15}$ The distinctions are often not explicit. There is little community discussion on residential energy consumption trends and their calculation. A detailed analysis of such trends would be of great service to the energy policy community.

${ }^{16}$ Note the sensitivity of such point-vs.-point comparison to the exact points compared: 2001 total estimated energy consumption in the United States was 38\% higher than in 1974 (compared to the aforementioned 25\% increase between 1978 and 2001). As to the difference between 1974 and 1978, this might be a matter of sampling variability (i.e., insignificant) or explained by economic factors, weather, or any number of things that make one year different from the next. Another example is given in the case study on refrigerators.
} 
when viewed from a distance, in terms of global consumption and global environmental damage, it lacks credibility; arguably, it could even make things worse, by providing a symbolic action that draws attention away from more important things.

For developing policy that reduces GHG emissions or addresses other environmental concerns, focusing too narrowly on the question "how can we promote energy efficiency?" is imprecise and sometimes even misleading. Asking "what can energy efficiency do for the environment, and how can it do this best?" is more precise. This means admitting that energy efficiency may not be able to achieve the claims made or implied for it, at least not on its own, and exploring how it might do better by coordination with other domains. Even when policy-relevant conclusions are ultimately needed, the problem of energy consumption cannot be sufficiently understood by starting from a selection of potential policy solutions. Nor should critiques of efficiency's progress toward reducing consumption, such as this one, be seen as ethical critiques of consumption. Instead, we want to ask, "what can energy efficiency, and energy efficiency policies, do well? What do they not do well? How can they be improved, and in conjunction with what other policies, in energy and other domains?"

\subsubsection{Social Messages of Marketing Efficiency}

Starting somewhere in the mid-1990s, energy efficiency marketing campaigns in the United States began to make a strong bid to distance themselves from "conservation," identifying conservation with sacrifice, old-fashionedness, and unpleasant memories of the 1970s energy crisis (Moezzi 1998). This strategy provided a new look for efficiency, shaping it into a primarily purchase-oriented rational practice, as contrasted with conservation, which was taken to mean the curtailment of needed energy services. In contrasting energy efficiency with sacrifice, a strong message about consumption choices comes through: the consumer deserves to consume. Consumption is, by definition, the duty of a consumer. The manner of consumption is a mode of self-expression. For a goal of improving the nominal efficiency of the technological devices and buildings in place, this seems very effective. However, it indirectly valorizes increasing energy services, which only questionably can be had without increasing the need for energy. In a highly market-based economy, efficiency must be something that is sold. While surveys may reveal that much of the population cares about environmental protection, there seems to be little reason to presume that any but a small niche of consumers will respond by changing their lifestyle. 


\subsection{Project Findings}

\subsection{Literature Review}

The authors reviewed the literature that relates energy efficiency, consumption, and policy from a social science perspective. There is a great deal of popular and academic work on consumption in general, but the social scientific literature on energy consumption itself is comparatively limited. A good deal of what has been written on it is found in the Proceedings of the Summer Studies of the American Council for an Energy Efficient Economy (ACEEE) and European Council for an Energy Efficient Economy (ECEEE), both of which are relatively inaccessible to consumption debates outside the field, such as in sociology. There is a tendency for consumption-oriented work in the energy field to concentrate on practical, project-oriented matters, often with little engagement with larger questions. For literature reviews of the field, see Lutzenhiser (1993) and Shove (2003). A brief review of some other important works is below.

Classical economic writers (Smith 1776) addressed the benefits to society from the production and consumption of goods, even as their contemporaries (Johnson 1759) critiqued the ideas of happiness resulting from material consumption. In the past century, writers linked consumption with status and coined the term "conspicuous consumption" (Veblen 1899) to reflect the use of consumption for social display. Veblen's term has become a favorite explanation of consumption for both popular and academic writers, but it is over- and often vaguely used, providing a useful but limited view. Several contemporary writers on American consumerist society have developed theories for the increased pace of material consumption and produced both academic and popular works on the subject (Goodwin 1997, Schor 1998, Cross 2000). A number of writers have noted the reaction to increased consumerism in the "voluntary simplicity" movement (e.g., Etzioni 1998), captured as well in relatively utopian hopes that there will be a morally based turn to reduced consumption. In popular and many academic works, there is a tendency to see consumption as an ethical matter, one that calls on individual disciplines to choose against consumption, battling against various market and social forces.

Rather than treating technology and people as largely separate elements determining consumption, it is more fruitful to attend to their interconnections. For example, historian Gail Cooper recounts efforts by the air conditioning pioneers to extend air conditioning beyond its industrial applications, marketing "comfort" as a means to accept air conditioning (Cooper 1998). Anthropologist Richard Wilk has looked at how culture defines consumption, including energy consumption (Wilk 2002). Anthropologist Willett Kempton has researched the impacts of different cultures on energy and material consumption (Kempton and Payne1997).

Jackson and Michaelis (2003) provide an excellent summary of "sustainable consumption," a term that entered the policy discourse at the Rio Summit (1992) and was reviewed in an article that looked at the global implications of increased consumption on the environment (Friends of the Earth 1998). In the past decade, social scientists in Europe have studied the linkages between consumption, lifestyle, and energy policy (Jeeninga et al. 1999; Shove and Wilhite 1999; Shove 2003; Jelsma 1999). The specific 
issue of whether energy efficiency reduces energy consumption has been addressed within economics (Howarth et al. 2000; Laitner 2004) and other commentators on energy and society (Rudin 1992; Moezzi 2000).

\subsection{Overview of California Residential Electricity Consumption}

This section begins with an overview of electricity consumption by end use in the California residential sector. The Energy Commission's Residential Appliance Saturation Survey (RASS) provides a survey sample-based saturation and modeled Unit Energy Consumption (UEC, e.g., kWh/year) for California residences, covering most major end uses. ${ }^{17}$ The 2003 survey was a combined effort from California's five investor-owned utilities (IOUs) (see Tobiasson et al. 2004 for a summary). The UECs were calculated using a conditional demand analysis that disaggregates total consumption in combination with survey responses on usage. For example, personal computer (PC) end-use consumption for each household is calculated based on user-reported number of PCs and hours used (CEC 2004).

To show what uses dominate in total consumption, Table 1 provides a list of residential end uses for which UECs are reported in the current RASS, sorted by their apparent importance to total single-family residential energy use in the state (indexed by "UEC * saturation," the "UEC per average household") (CEC 2004). Similar data for other housing types are available, but, for brevity, this section focuses on single-family results. To compare these results to other estimates, the last two columns include estimates from Brown and Koomey (2003). The end use categories of the two analyses are not precisely aligned with the RASS categories, but comparisons are still useful. The total electricity consumption shown in Table $1(4,948 \mathrm{kWh} / \mathrm{yr})$ is $70 \%$ of the total average electricity consumption for single-family residences $(7,105 \mathrm{kWh} /$ year). The top four end uses in the list - refrigerators, central air conditioners (CAC), televisions (TVs), and PCs - account for more than half of the total $\mathrm{kWh} / \mathrm{year}$ contributions of the end uses, and each has a saturation of $75 \%$ or above. The high consumption estimates for TVs and PCs are striking, and are substantially higher than EIA estimates from earlier years, even on a unit basis (EIA 1999). ${ }^{18}$ Pool pumps, second refrigerators, electric dryers, and freezers are ranked next, each accounting for $5 \%$ to $8 \%$ of the total comprised by the list (i.e., of end uses itemized in the list). These end uses have relatively high UECs but only moderate saturation, and all are covered by energy efficiency policies (CEC 2004). Of the remaining items on the list, there are a few high-saturation end uses (e.g., microwave, furnace fan, outdoor lighting, clothes washer, and dishwasher), but these have limited impact because of their low UECs.

\footnotetext{
${ }^{17}$ The EIA's RECS also supplies saturation and estimated consumption and expenditures by demographic categories for residential end uses for California; however, the sample size is not large (the sample is 541 houses for 2001, but when disaggregated by house type, etc., and when climatic variety is considered, to the extent necessary, this is a small sample for many purposes).

${ }^{18}$ EIA (1999) uses $307 \mathrm{kWh} /$ year per household for color TV and $317 \mathrm{kWh} /$ year for PC per household with the given end use, compared to $519 \mathrm{kWh} /$ year, respectively, according to RASS. There may be some confusion between saturation and number/household.
} 
Table 1. Residential end uses in California single-family homes (RASS columns), sorted by their contribution to residential sector electricity use

\begin{tabular}{|c|c|c|c|c|c|c|}
\hline \multirow[b]{2}{*}{ End Use } & \multirow[b]{2}{*}{$\begin{array}{c}\text { UEC } \\
{[\mathrm{kWh} / \mathrm{yr}]}\end{array}$} & \multirow[b]{2}{*}{$\begin{array}{c}\text { Saturation } \\
{[\%]}\end{array}$} & \multirow[b]{2}{*}{$\begin{array}{c}\text { UEC * } \\
\text { Saturation }\end{array}$} & \multirow[b]{2}{*}{$\begin{array}{c}\text { Percentage } \\
\text { of Total } \\
(\%)\end{array}$} & \multicolumn{2}{|c|}{$\begin{array}{l}1999 \text { Residential } \\
\text { Consumption }^{\text {(a) }}\end{array}$} \\
\hline & & & & & TWh & $\begin{array}{c}\text { Percentage } \\
\text { of } \\
\text { Residential } \\
\text { Total }(\%)\end{array}$ \\
\hline First Refrigerator & 824 & 100 & 824 & 17 & $13.7^{(\mathrm{b})}$ & 18 \\
\hline Central A/C & 1,423 & 46 & 655 & 13 & $4.8^{(\mathrm{c})}$ & 6 \\
\hline $\mathrm{TV}$ & 519 & 96 & 498 & 10 & 3.4 & 5 \\
\hline $\mathrm{PC}$ & 578 & 75 & 434 & 9 & n.a. & \\
\hline Pool Pump & 2,671 & 14 & 374 & 8 & $4.1^{(\mathrm{d})}$ & 5 \\
\hline $\begin{array}{l}\text { Second } \\
\text { Refrigerator }\end{array}$ & 1,245 & 25 & 311 & 6 & (incl. above) & \\
\hline Dryer & 713 & 34 & 242 & 5 & 5.7 & 8 \\
\hline Freezer & 937 & 24 & 225 & 5 & 2.5 & 3 \\
\hline Outdoor Lighting & 284 & 67 & 190 & 4 & n.a. & \\
\hline Water Heat & 3,079 & 5 & 154 & 3 & 4.2 & 6 \\
\hline Microwave & 140 & 97 & 136 & 3 & n.a. ${ }^{(\mathrm{e})}$ & \\
\hline Range/Oven & 301 & 41 & 123 & 2 & 3.6 & 5 \\
\hline Clothes Washer & 127 & 95 & 121 & 2 & 0.7 & 1 \\
\hline Spa (Electric Heat) & 1,719 & 7 & 120 & 2 & $\begin{array}{l}\text { See Pool } \\
\text { Pump }\end{array}$ & \\
\hline Furnace Fan & 162 & 68 & 110 & 2 & & \\
\hline Aux. Elec. Heat & 296 & 28 & 83 & 2 & & \\
\hline Spa & 467 & 13 & 61 & 1 & $\begin{array}{l}\text { See Pool } \\
\text { Pump }\end{array}$ & \\
\hline Conv. Electric Heat & 1,494 & 4 & 60 & 1 & & \\
\hline Dishwasher & 84 & 70 & 59 & 1 & 2.0 & 3 \\
\hline Well Pump & 862 & 5 & 43 & 1 & & \\
\hline Evap. Cooling & 688 & 5 & 34 & 1 & (incl. above) & \\
\hline Room A/C & 227 & 15 & 34 & 1 & (incl. above) & \\
\hline Home Office & 148 & 20 & 30 & 1 & & \\
\hline Water Bed & 840 & 2 & 17 & 0 & 2.1 & 3 \\
\hline HP Electric Heat & 1,077 & 1 & 11 & 0 & & \\
\hline Solar Water Heater & 1,708 & 0 & 0 & 0 & & \\
\hline Total & & & $4948 \mathrm{kWh}$ & $100 \%$ & $75.4 \mathrm{TWh}$ & \\
\hline
\end{tabular}

Source: CEC 2004; Brown and Koomey (2003); authors' calculations
(a) Brown and Koomey (2003)
(b) This number is for all refrigeration, not just first refrigerators.
(c) Total for air conditioning, including types other than central air.
(d) Total for pools and spas.
(e) Included in the row for "Ranges/Ovens," for which we use Brown and Koomey (2003) total for the
"Cooking" category. 


\subsection{Three Case Studies}

This section develops case studies on housing, refrigerators, and air conditioners to explore linkages between energy efficiency, consumption, and policy. Each of these case studies initiates discussion on the strengths and limitations of energy efficiency as a policy tool to promote lower energy consumption and carbon emissions, while asking questions about the availability and quality of data, and the limitations of data analysis.

\subsubsection{Housing as a Case Study}

The housing discussion starts by looking at an even bigger picture- the increase in U.S. carbon emissions from all sectors, of which electricity consumption in homes accounts for about 14\%. ${ }^{19}$ Between 1973 and 1997, U.S. carbon emissions increased 25\%, from 1224 to 1480 million metric tons equivalent (Figure 1).

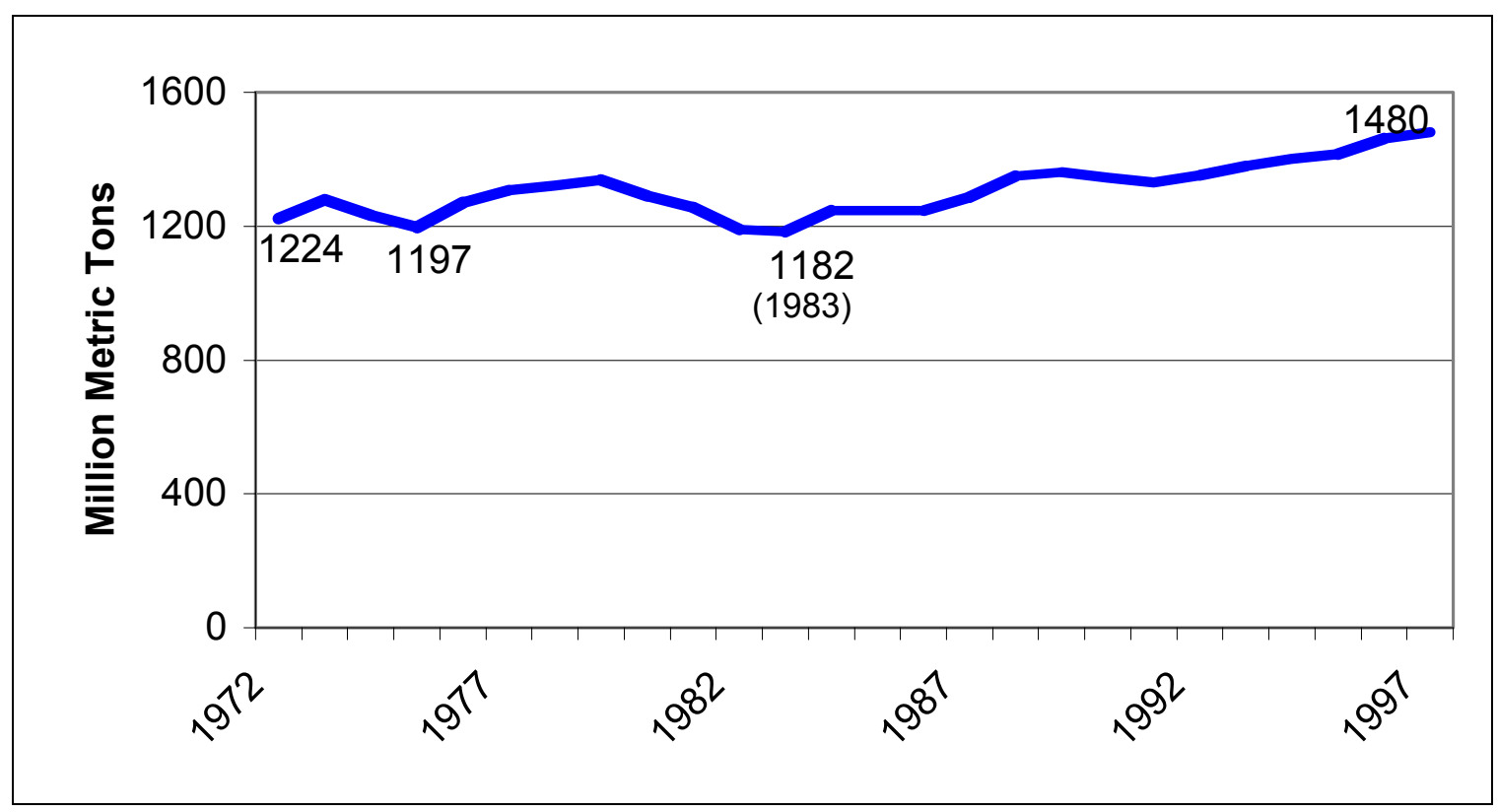

Source: EIA 1997

Figure 1. U.S. carbon emissions (million metric tons carbon equivalent) across all sectors

In the U.S. residential sector, there is a similar increase in carbon emissions, both for the sector as a whole, and for residential electricity use (Figure 2), although the data are for a more limited period.

\footnotetext{
${ }^{19}$ Calculated on the basis of 2002 figures cited in Emissions of Greenhouse Gases in the United States 2003 (EIA 2004c (http://www.eia.doe.gov/oiaf/1605/ggrpt/cdemissions tbls.html): 825.6 million metric tons carbon dioxide emitted from residential electricity consumption in the home, divided by 5824.6 million metric tons total carbon dioxide emissions in the United States. Carbon dioxide emissions account for about $83 \%$ of total GHG emissions in United States, in terms of global warming potential (EIA 2004c).
} 


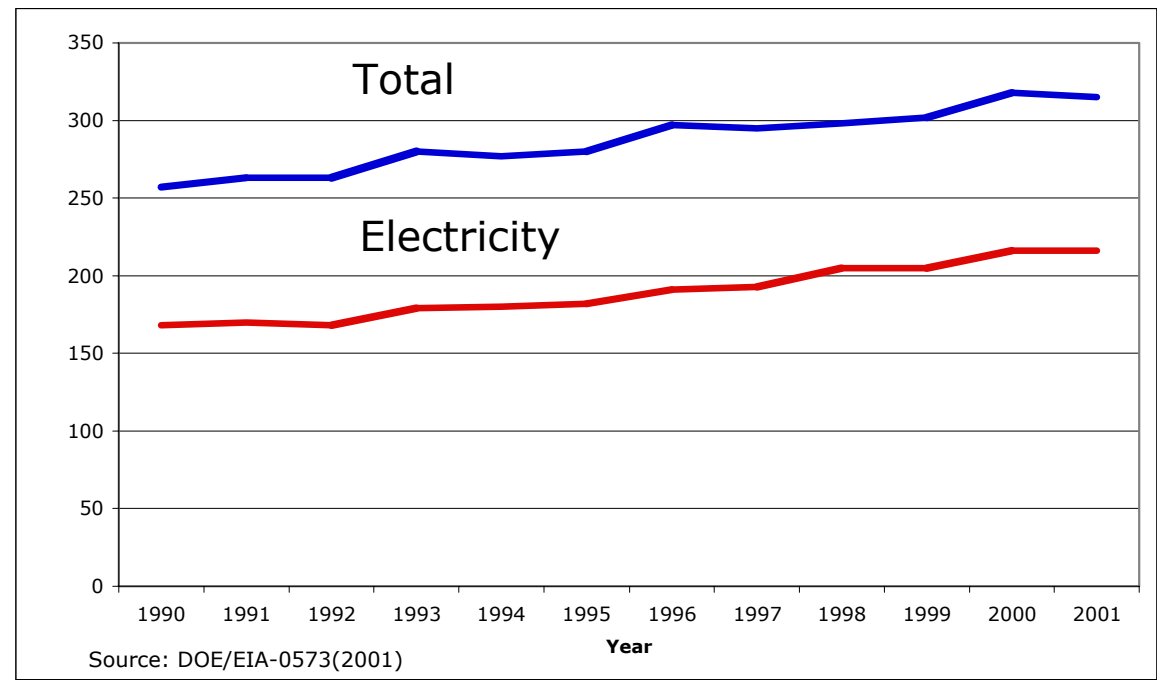

Source: EIA 2004a

Figure 2. U.S. carbon emissions from residential sector energy consumption

The explanation for the increase does not lie solely in population growth. Per capita carbon emissions for the U.S. residential sector have also increased, in terms of both total emissions and those attributable to electricity use (Figure 3). That is, carbon emissions have increased more than population has.

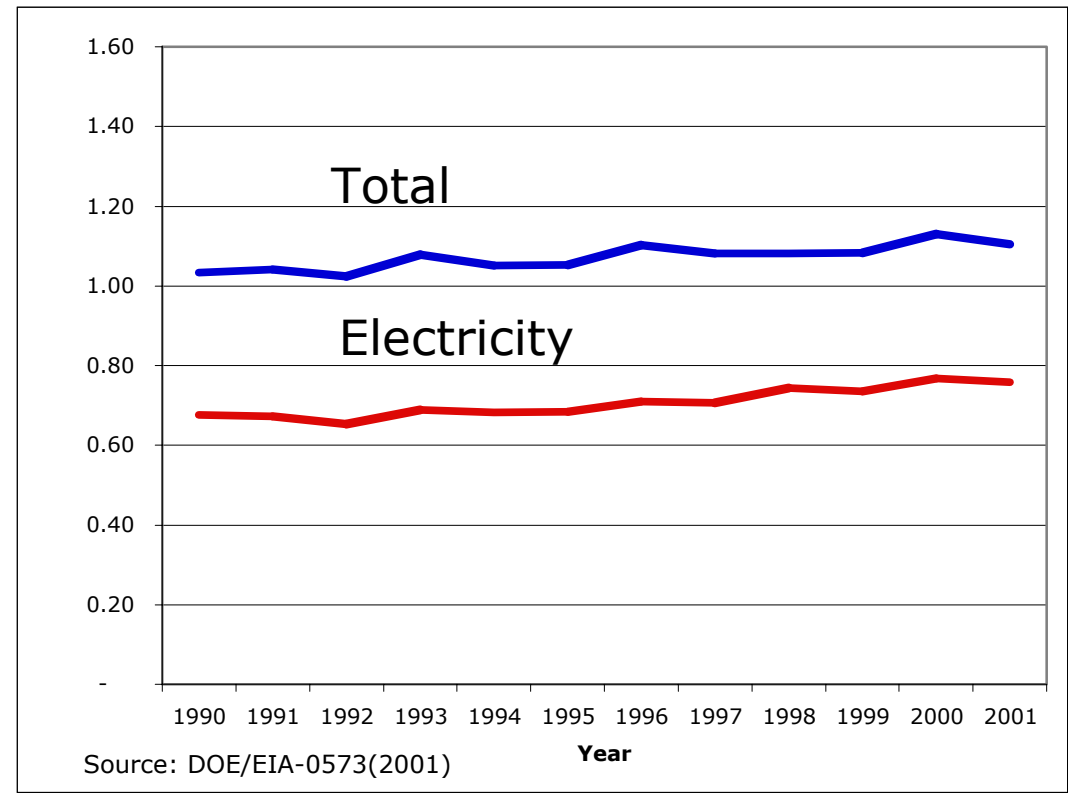

Source: EIA 2004a

Figure 3. U.S. per capita carbon dioxide emissions from residential sector energy consumption 
Considering U.S. primary energy consumption from 1949 to 2001, the rate of consumption generally increased until the oil price shocks of the mid-1970s and early 1980s, when the pattern reversed for a few years (Figure 4). From 1973 to 1997 when carbon emissions increased $25 \%$, total energy increased 20 percent.

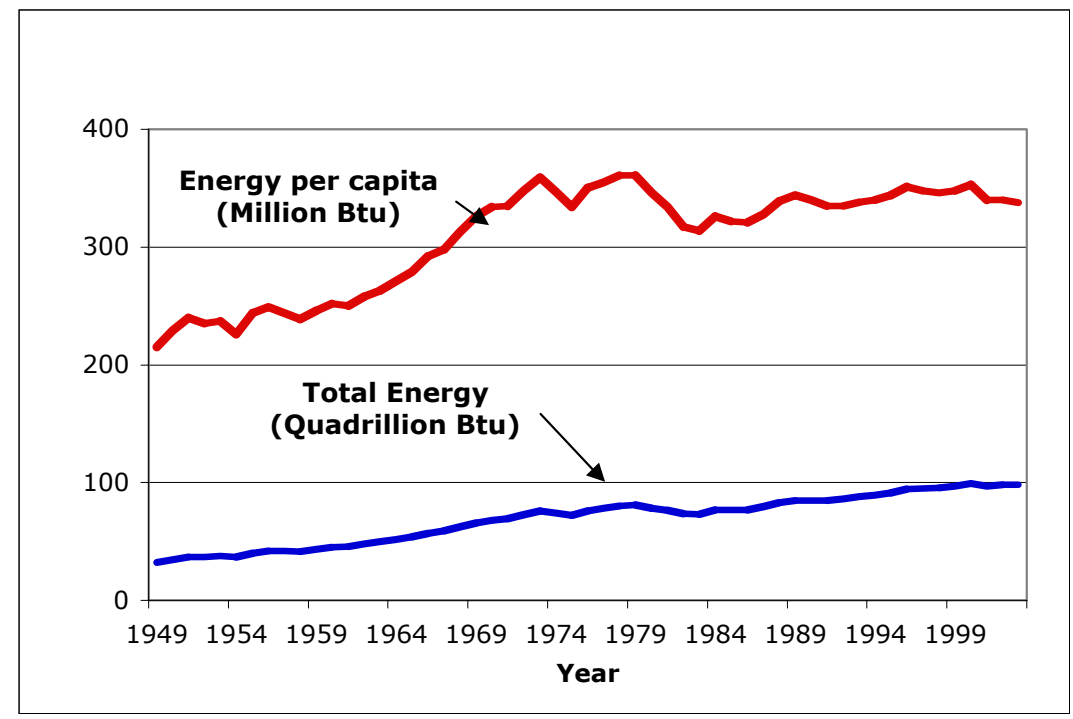

Source: EIA 2004a

Figure 4. U.S. energy use total and per capita, 1949-2003

Per capita energy use also increased from 1949 to 1973 (Figure 4). If we look at the historic trend in residential energy use per capita by fuel type, we see part of the reason for this increase (Figure 5).

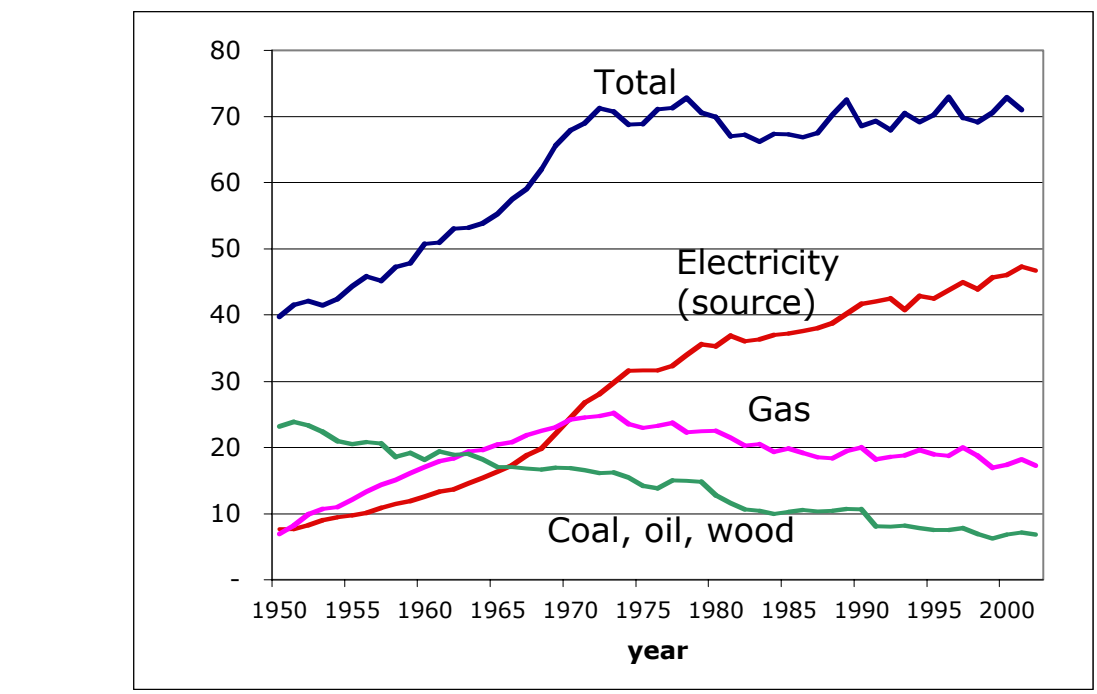

Source: EIA 2004a

Figure 5. U.S. residential energy use (primary) per capita 1949-2003 
If this data is disaggregated further, and the study focuses on specific end uses, it becomes clear that the growth in residential electricity use is mostly due to greater appliance usage and/or more energy use per appliance. Three caveats are in order here. The first is that the data reported in Figure 6 are for site energy, not source energy, which is the usual way that end use data are reported, but it obscures the impact of electricity and the resulting carbon emissions. Second, while RECS end-use data is a national reference for policy purposes, the estimates are based on modeled decompositions of total energy consumed, rather than being based on end-use measurements; as mentioned above, these estimates are valuable - the best available - but may not be accurate even on average. Third, because the data presented are averages, they do not capture the variability of consumption across time or household, which is critical to understanding why things are changing and how these changes might be addressed by policy.

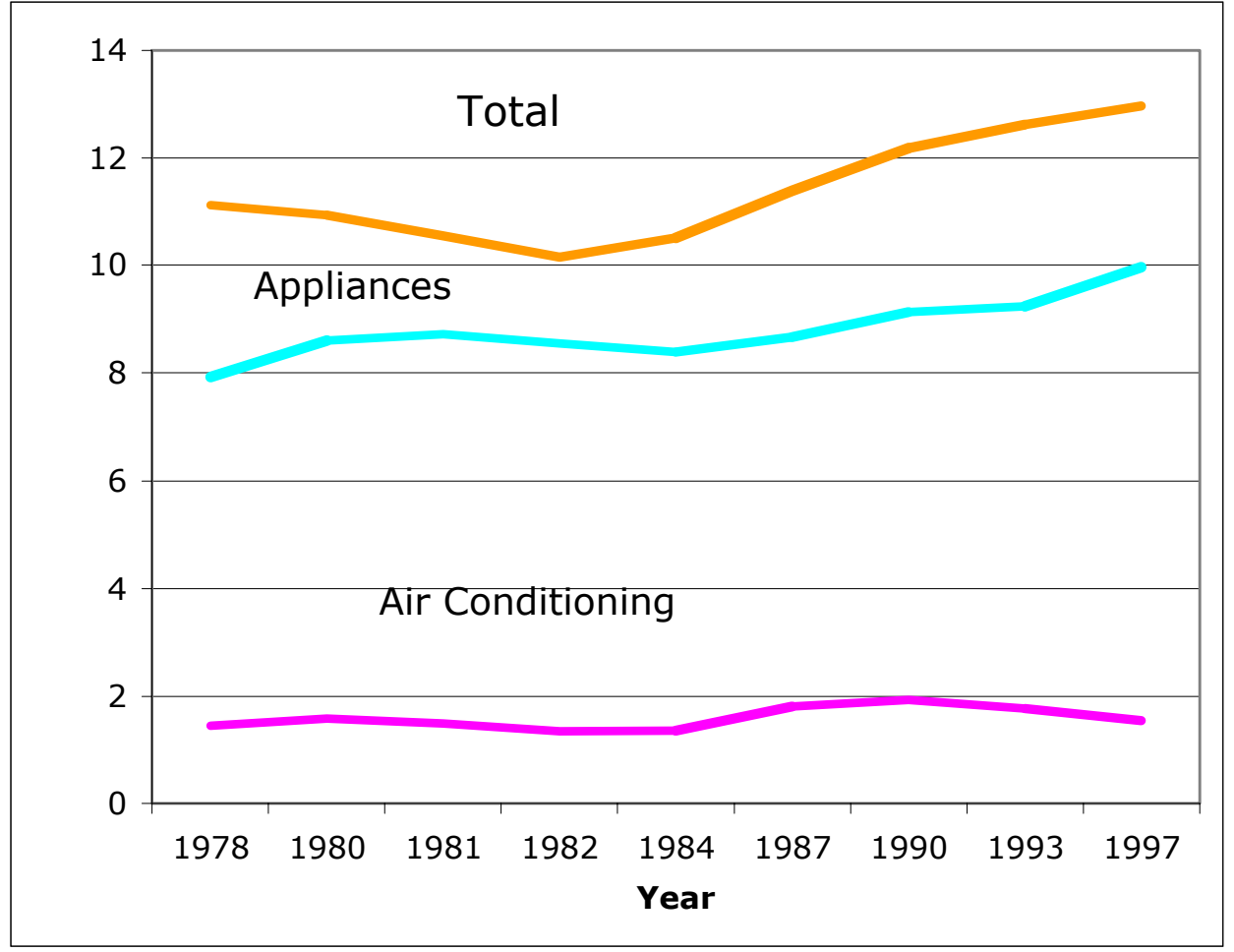

Source: EIA 2004a

Figure 6. U.S. end-use, per-capita residential electricity consumption (site) 1978-1997

The data for California shows a slight increase in electricity consumption, but at a lower rate than for the United States as a whole (Figure 7) and a nearly level per capita electricity consumption, with a dip in 2001 due to the statewide electricity crisis (Figure 8). 


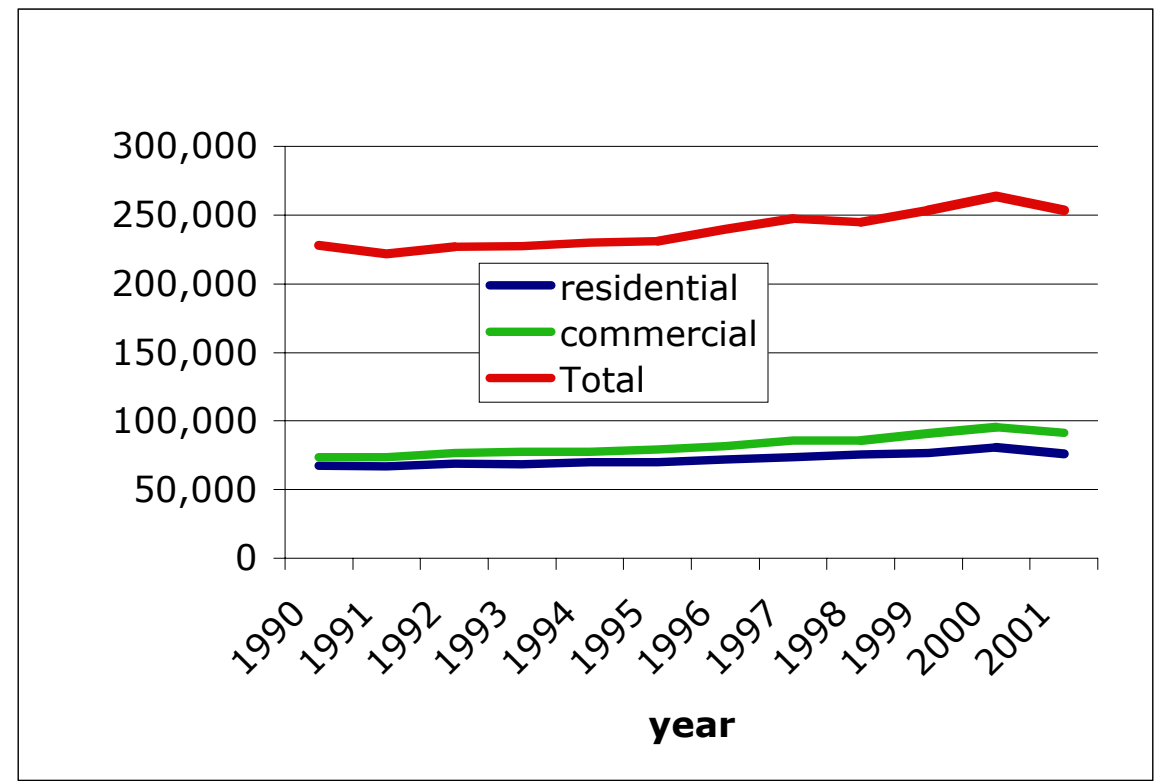

Source: California Energy Commission 2002

Figure 7. California electricity consumption by sector, 1990-2001

Brown and Koomey (2003) analyzed trends in electricity consumption for California, 1980-2000. Over these years, residential electricity consumption grew 49\%, a slightly lower growth rate than the 54\% observed for electricity consumption over all sectors (Brown and Koomey 2003). However, the rate of growth of residential electricity consumption surpassed the rate of growth of housing units $(32 \%)$ and of state population (42\%). Figure 8 shows California trends in per capita electricity consumption for residential and commercial sectors. Residential peak load increased less, 40\% between 1980-2000, which is much lower than the 57\% rate observed for peak load over all sectors. The growth rates were uneven though, due to uncertainties in the data. On the one hand, both electricity consumption and peak load growth rates were substantially lower than the observed growth rate in gross state product, which more than doubled (an $119 \%$ increase) over the same 20 years. On the other hand, this speaks to a decrease in energy intensity per unit produced, which is not a measure of efficiency. Thus, we are left with the question: If efficiency has increased, why has electricity consumption in the residential sector increased more than both the number of housing units and the population? 


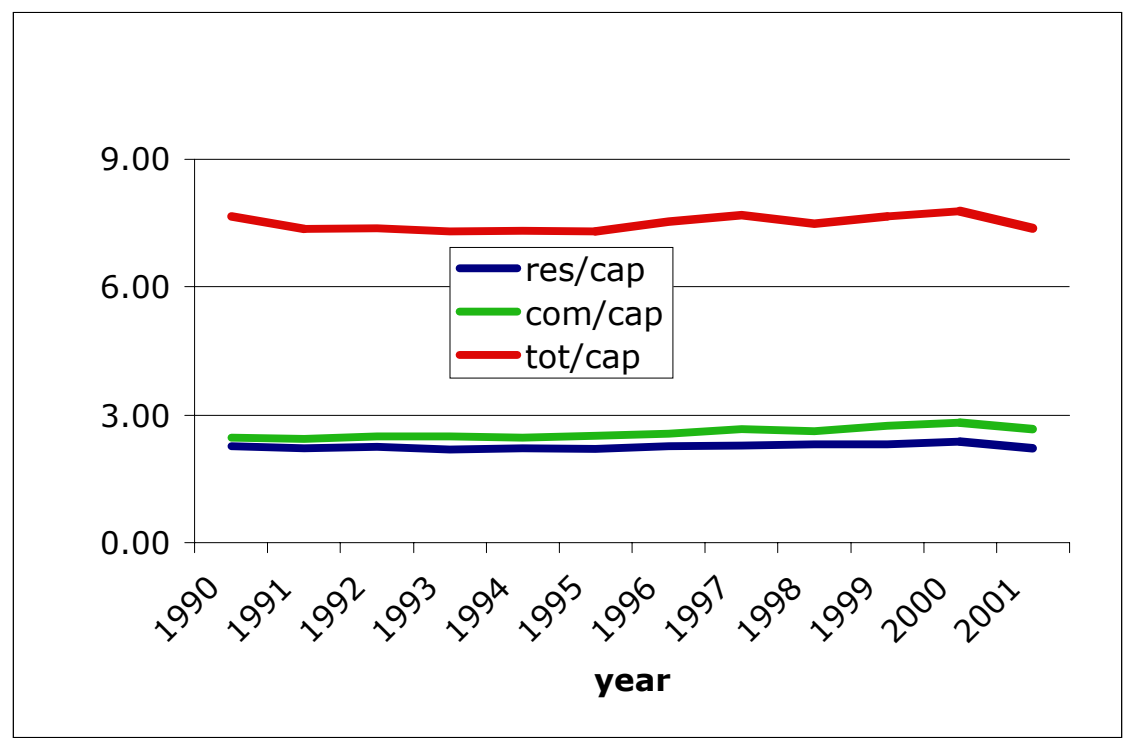

Source: California Energy Commission 2002

Figure 8. California per capita electricity consumption by sector, 1990-2001

Certainly, part of the increase in energy consumption might be explained by the increase in floor area. In 1950, the average floor area for a new house was 1,000 $\mathrm{ft}^{2}$. By the year 2000, the average floor area for a new house had more than doubled to $2,200 \mathrm{ft}^{2}$ (Figure 9).

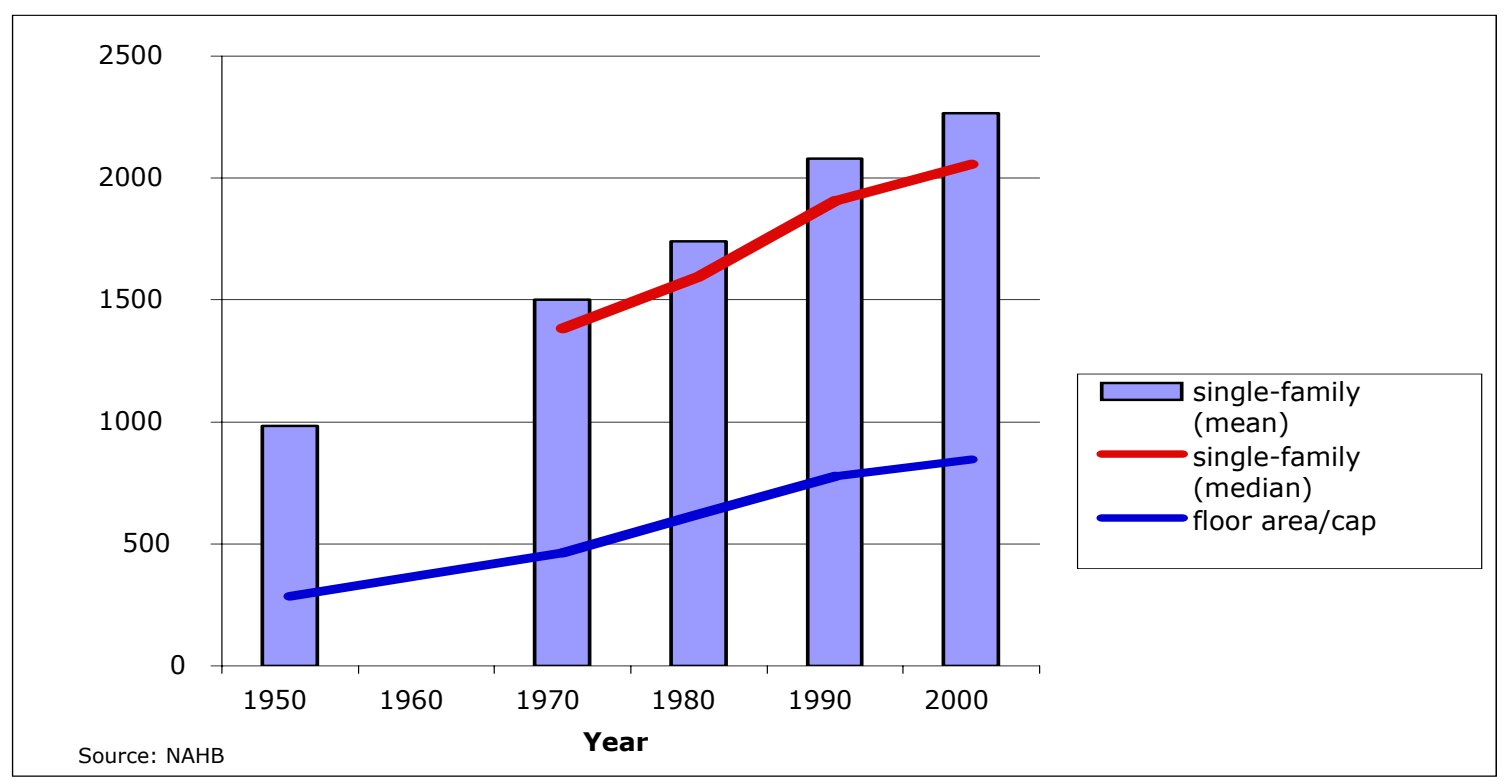

Source: NAHB 2003

Figure 9. U.S. house size (floor area) mean and median 1950-2000

Over this period, the number of people per household decreased, so that the average floor area per capita has increased by more than a factor of three, from 286 to $847 \mathrm{ft}^{2} /$ capita. In 
theory, bigger houses are more efficient in enclosing space because of their lower surface-to-volume ratios. More practically, large houses today have complex perimeters (e.g., more bay windows, dormers, and other features that lead to increased surface area) and are consequently less efficient in terms of volume-to-surface area. Complex surface geometries lead to greater air leakage and to increased surface area for heat loss and heat gain. Bigger houses tend to have more things - more appliances, more equipment, more everything. For houses with air conditioning, the energy load is dominated by air conditioning rather than electronics, and air conditioning consumption is theoretically related to volume. The logical conclusion of these arguments is that bigger buildings filled with more people provide the most efficient mode of housing, and communal or multi-family housing becomes environmentally attractive, all other things being equal. ${ }^{20}$

This study did not have data for the floor area of new housing starts for California, but by looking at the West census region, the same pattern of growth can be seen, so that by the year 2000 , over $50 \%$ of new houses were larger than $2,000 \mathrm{ft}^{2}$ (Figure 10).

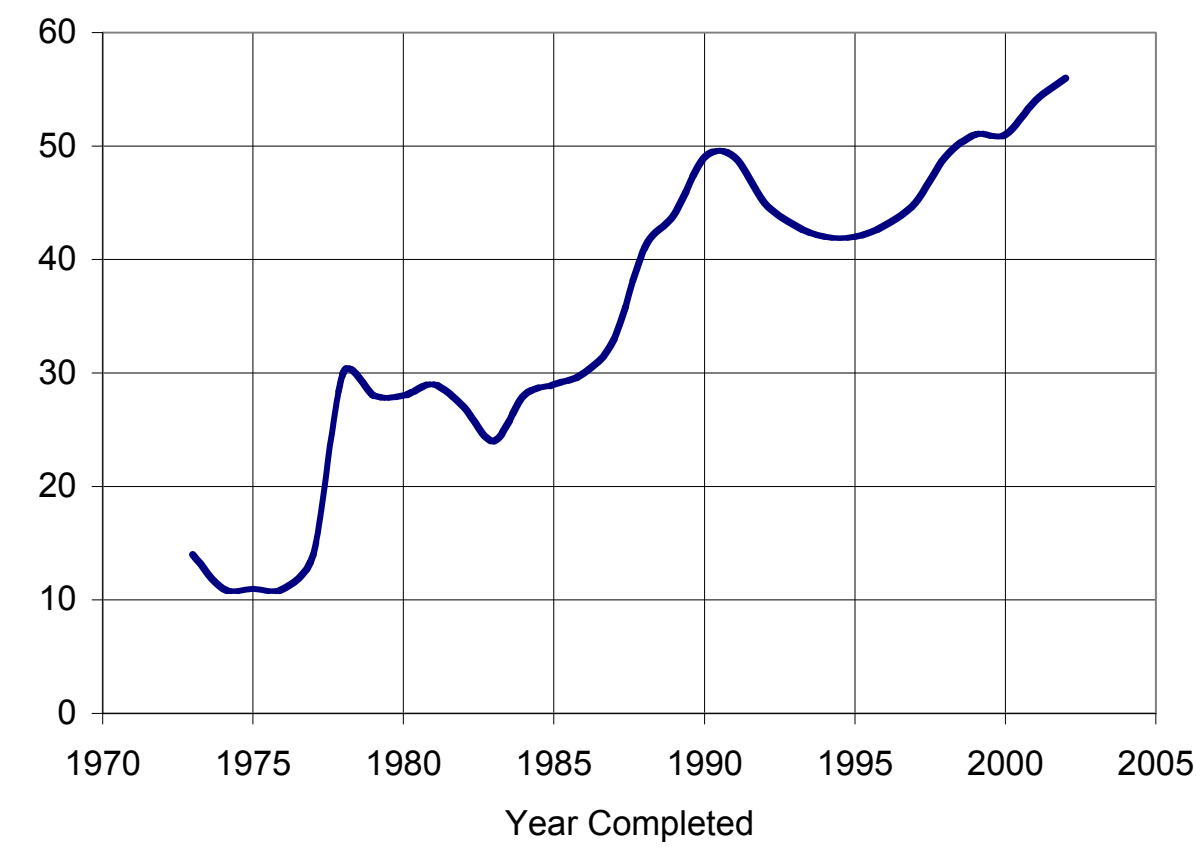

Source: U.S. Census Bureau 2003.

Figure 10. Percent of new one-family houses 2,000 square feet or larger, West census region (1970-2002)

As the coastal urban areas approach saturation for buildable (single-family) lots, housing markets in California have moved inland, and houses have not only been getting larger, but have been built in the hotter interior, requiring more air conditioning. In 2003, Riverside County's population grew from 1.719 million people to 1.777 million people,

\footnotetext{
${ }^{20}$ However, multi-family housing generally suffers from a bad reputation in the United States (NAHB 2004), while owning a single-family home is highly supported and encouraged socially and economically.
} 
or by 3.4 percent, more than double the 1.5 percent increase seen statewide (California Department of Finance 2004). "We've been projecting a 4-5 percent increase in load on an annual basis," said Steve Badgett, Riverside Public Utilities assistant director for energy delivery. "Our challenge is to stay two to three years ahead ... We're seeing the 3,000- to 4,000-square-foot home to be the norm out here," said Badgett (California Energy Circuit 2004).

Figure 11 shows the distribution of all U.S. households by floor area, with the large number of houses in the largest category. The special class of very large homes (e.g., over 4,000 $\mathrm{ft}^{2}$ - the so-called "monster" houses) is discussed later in this section.

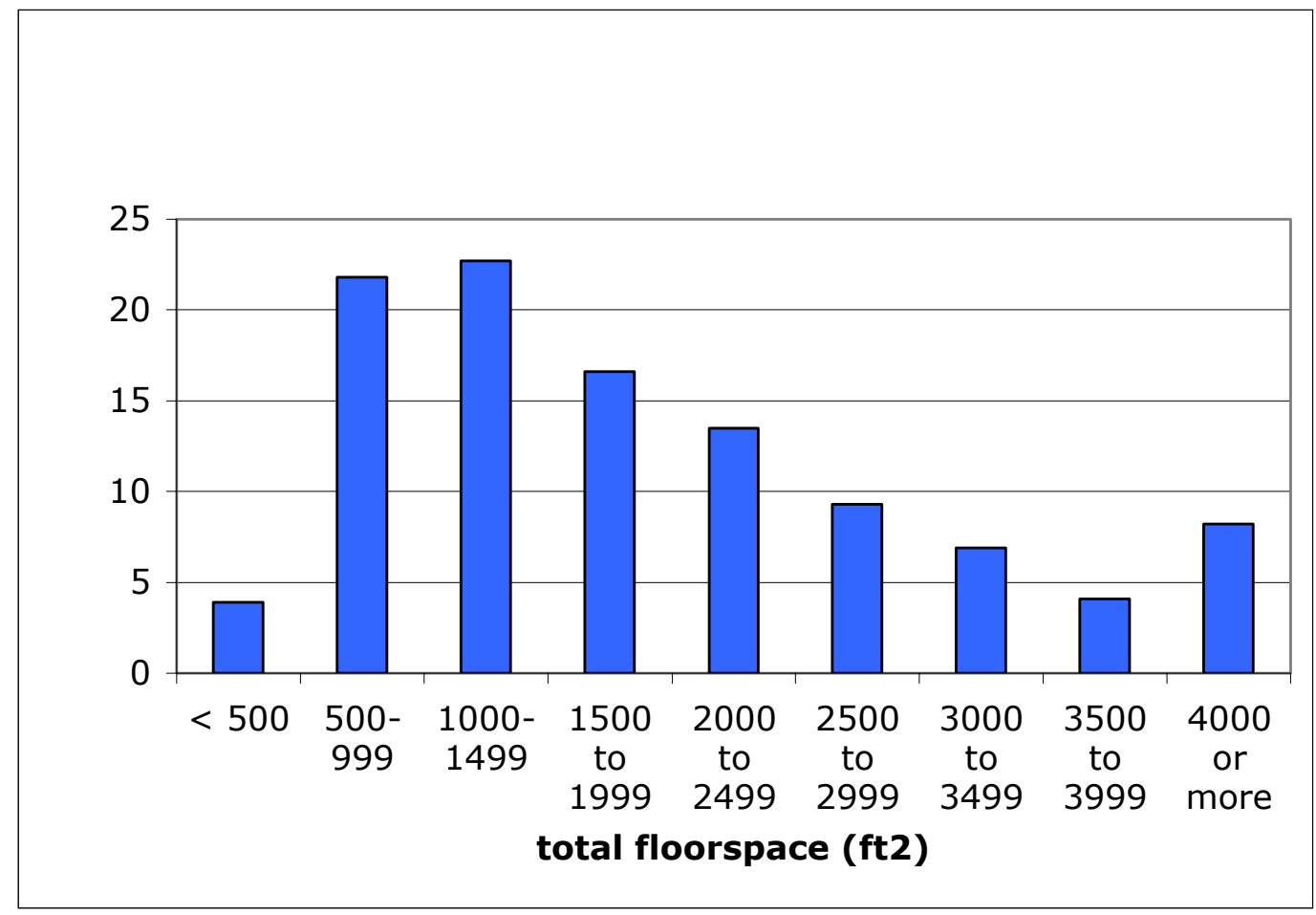

Source: EIA 2004b

Figure 11. 1999 distribution of U.S. housing units by floor area

When looking at the energy consumption for the entire housing sector, it becomes apparent that a disproportionate amount of energy is used in the largest houses. Houses over $4,000 \mathrm{ft}^{2}$ represent $8 \%$ of the stock (Figure 11) but consume 13\% of the energy (Figure 12). 


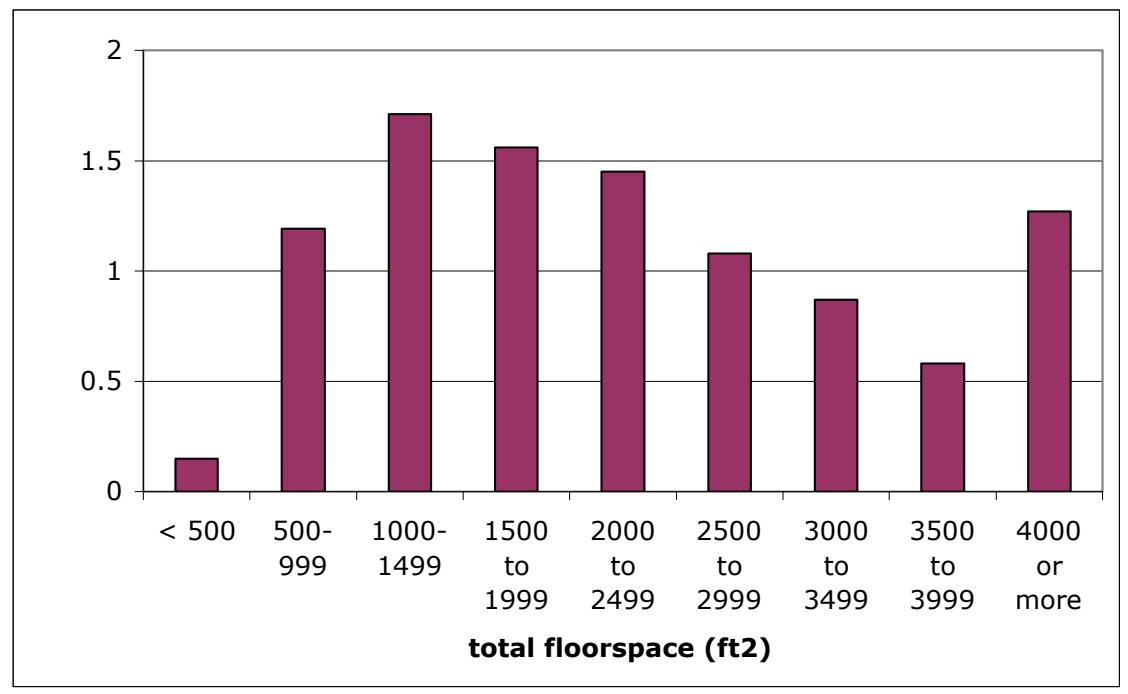

Source: EIA 2004b

Figure 12. 1999 total site energy consumption of U.S. housing units by floor area

When looking at energy consumption per household, one can see that it scales with the size of the house: larger houses do use more energy (Figure 13). On average, a housing unit 8 times larger in floor area uses 4 times more energy.

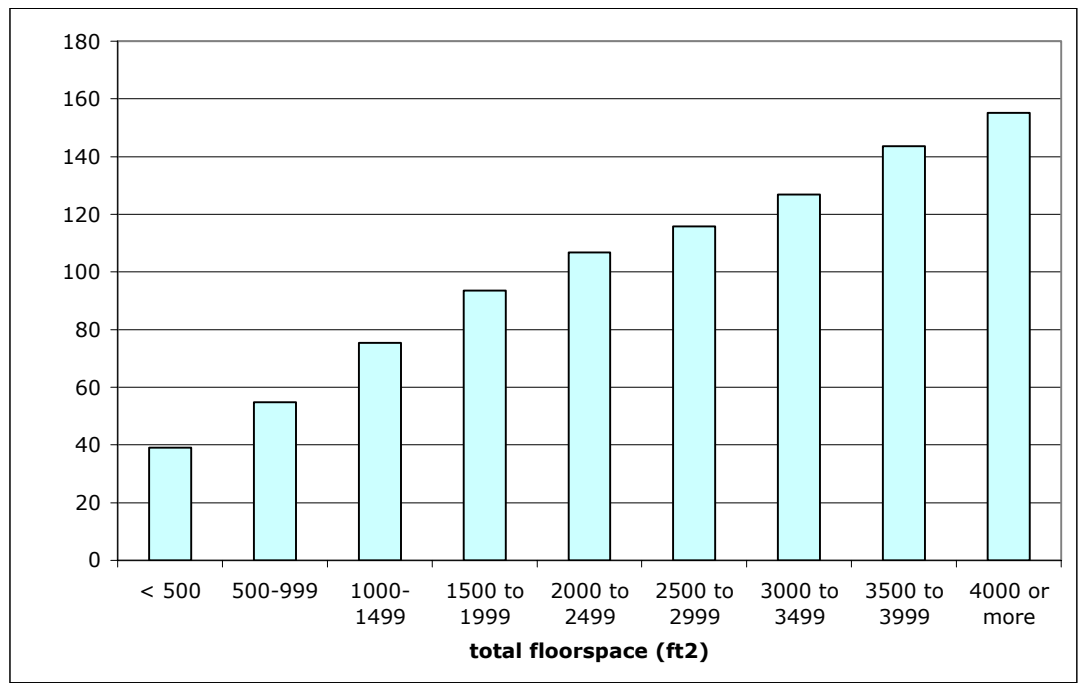

Source: EIA 2004b

Figure 13. 1999 energy consumption of U.S. houses per household by size of house

Figure 14 shows energy consumption per square foot by size of house, a measure of energy intensity. A small house $\left(<500 \mathrm{ft}^{2}\right)$ uses 90 thousand Btu (KBtu)/ $\mathrm{ft}^{2}$ compared to $30 \mathrm{KBtu} / \mathrm{ft}^{2}$ for a larger house $\left(4,000 \mathrm{ft}^{2}\right.$ or more $)$, so does that make the smaller house less efficient? The energy use of the larger house is four times larger than the smaller one, but its energy intensity is only one third. This issue will be covered in more detail 
when this section discusses how energy codes are based on energy use per square foot, and not on total energy consumption.

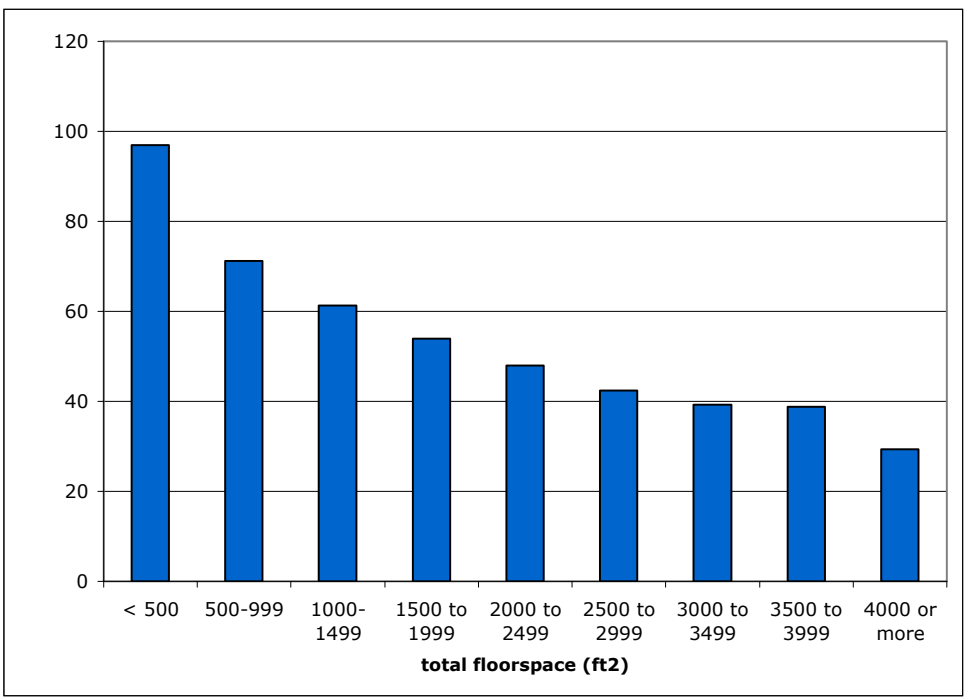

Source: EIA 2004b

Figure 14. U.S. residential energy use (site) per square foot by house size

Figure 15 shows that energy use per household member increases with house size. Thus, larger houses have higher energy consumption, not because there are more people in them, but because these people, or the things and activities within the household, consume proportionately more energy than for people living in smaller houses. A small inefficient house may often use less energy and materials than a large efficient house.

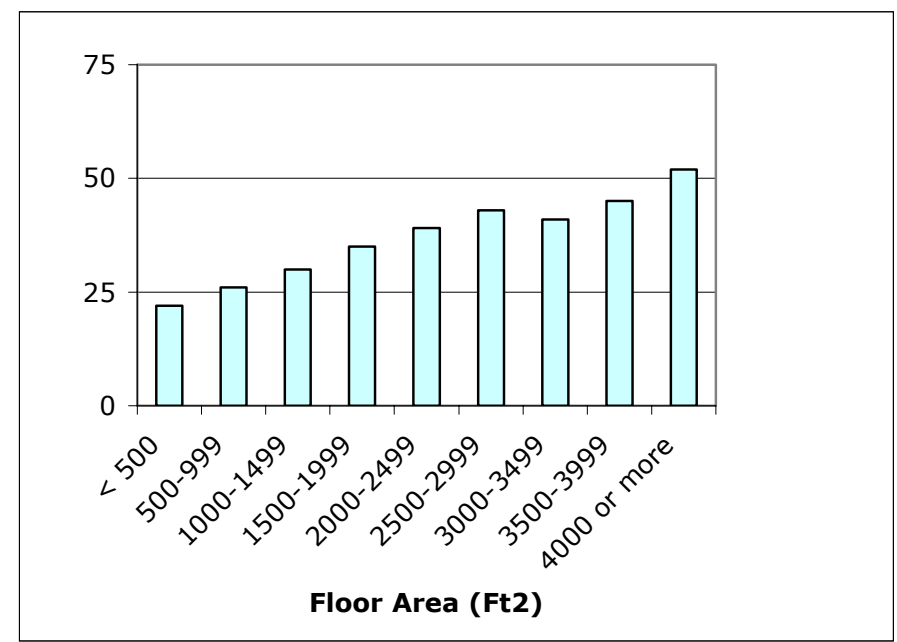

Source: EIA 2004b

Figure 15. U.S. 2001 residential energy use (site) per household member by house size 
Energy analysts often default the residential sector to the single-family residence, which makes up $68 \%$ of the housing units in the United States. Other housing types (e.g., row houses, multifamily (MF) homes, mobile homes) use less energy per average dwelling. Figure 16 shows the energy use per household for different housing types, with singlefamily housing having the largest share of total energy consumption, and large apartment buildings (which have the smallest units) having the smallest energy consumption per household.

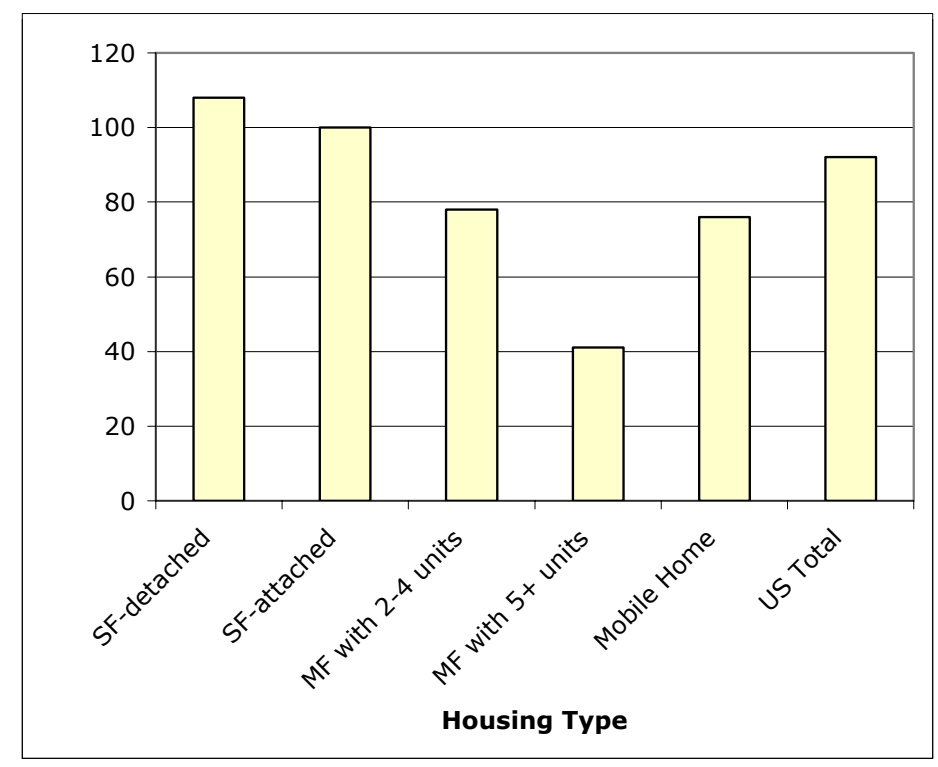

Source: EIA 2004b

Figure 16. U.S. 2001 total residential energy use (site) by household and housing type

When normalizing energy consumption by floor area, it becomes clear that most housing types have roughly the same site energy consumption per square foot of floor area (the exception being mobile homes) (Figure 17). Again, these numbers obscure vast differences in variables such as number of people per household, age and efficiency of appliances, household income, and other factors, so they do not explain why the categories differ. 


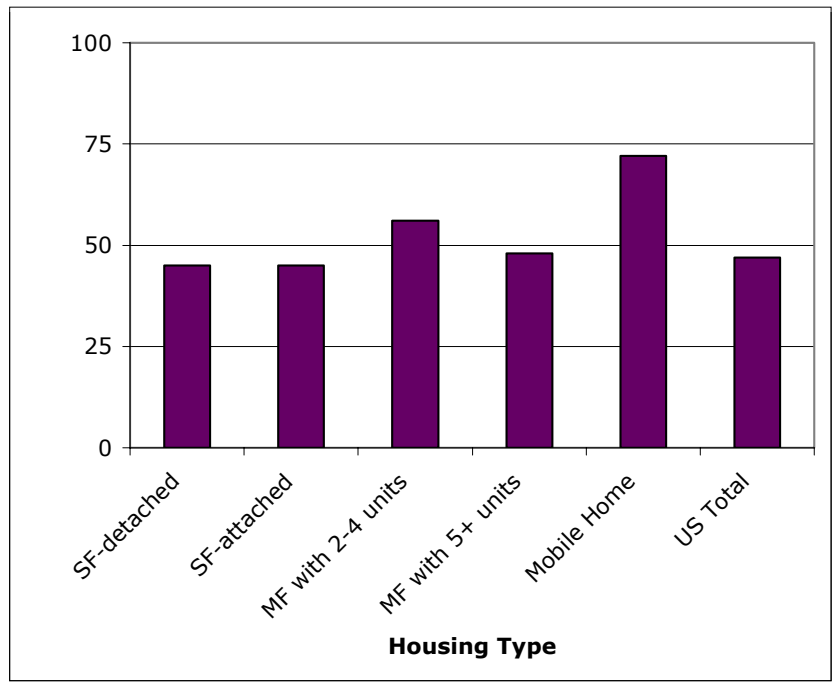

Source: EIA 2004b

Figure 17. U.S. 2001 residential energy use (site) per floor area by housing type

As for residential energy use per capita by housing type, the smaller units (e.g., large apartment buildings and mobile homes) have the smallest energy use per capita (Figure 18). There are multiple confounding effects here, including income, reduced heat loss area, higher insulation levels, and others, that make it difficult to pinpoint the factors that are responsible for the lower energy use, to the extent that expressing energy consumption as the result of "factors" makes sense.

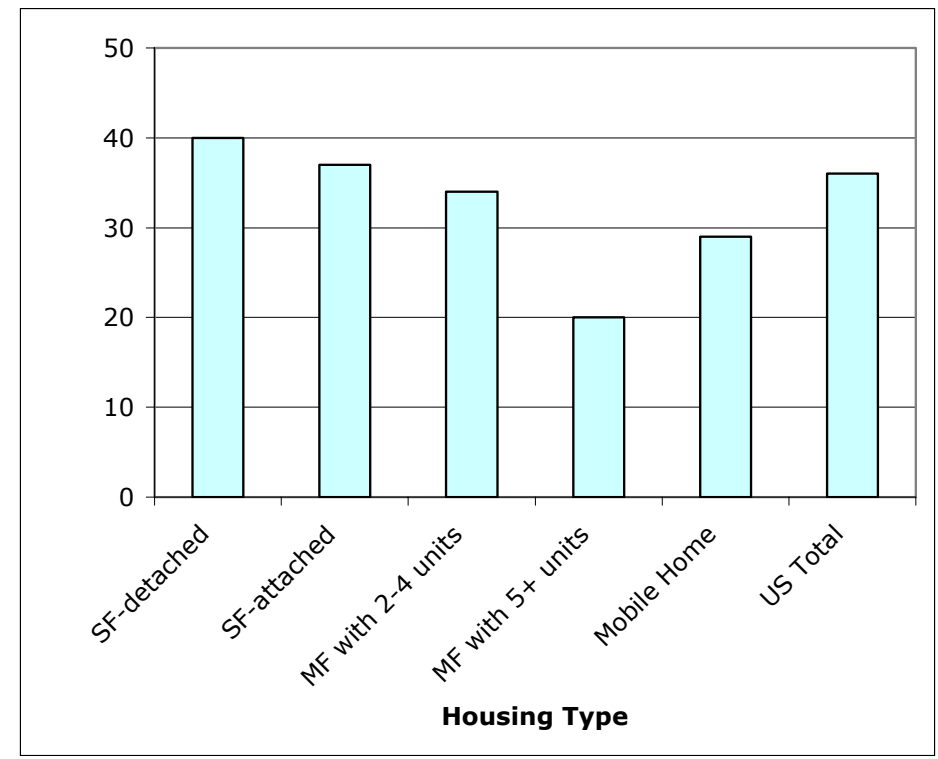

Source: EIA 2004b

Figure 18. U.S. 2001 residential energy use per household member by housing type 
Monster homes. Since the late 1990s, there has been intense public discussion about socalled "monster homes," in various parts of the United States, the San Francisco Bay Area among them. They are a phenomenon that "everybody loves to hate," as a 1999 article in the San Francisco Chronicle puts it, even if relatively few would mind being in a position to have one. ${ }^{21}$ The starting points of this discussion are a multitude of individual cases where the owner applies for a construction permit or exemption, leading to various giants on hilltops or in-filled in "what-used-to-be-normal" neighborhoods. They are exemplars of conspicuous consumption, a sociological term that in popular usage has very negative connotations, at least on the surface. The intensity of interest, and (psychoanalysis would say) the conflict of emotions involved, is evidenced by the sizeable collection of slang associated with these homes: "McMansion," "starter castle," and "big hair house." 22 These terms also reflect the changing nature of monster homes, from a few examples of custom construction by the very wealthy, to a series of more mundane production consumption targeted at the upper-middle incomes. In the Western census division, the percentage of new single-family construction greater than $3,000 \mathrm{ft}^{2}$ doubled, from $10 \%$ in 1988 to $21 \%$ in $2001 .^{23}$ A similar phenomenon has been noted in some other countries as well, for example, Australia (Nozzi 2002).

If these houses have become a symbolic as well as a practical use for their owners, they have also become a rallying point for concerns about "supersizing," that is, growth in consumption and energy services that are, by implication, unneeded. ${ }^{24}$ While the excess size of a few homes of the very wealthy will not make much difference to total residential energy consumption, they have come to represent the idea that Americans will demand bigger and bigger things in all realms.

Their presence also begins to "ratchet up" expectations for house size, so that typical houses will become bigger and bigger. Second, they are a conspicuous example of a case in which consumption trumps efficiency; that is, while the large homes may very well meet energy efficiency standards for construction, they will likely generate substantially more consumption than a moderate-sized home, even one that is older and, from a technical standpoint, less efficient.

\footnotetext{
${ }^{21}$ The quote continues, “... except the folks who own them or are clamoring to buy them.” Gaura, M. A., and C. Zinko. 1999. "Invasion of the Monster Homes. Silicon Valley trend spreads - raze a small house, build a mansion." San Francisco Chronicle 8 November 1999. http://www.sfgate.com/cgi-bin/article.cgi?file=/chronicle/archive/1999/11/08/MN68431.DTL.

${ }^{22}$ The Wordspy website (Wordspy 2004) provides an analysis of these and several other terms.

${ }^{23}$ Source is the C-25 data from the U.S. Census Bureau, Manufacturing and Construction Division (U.S. Census Bureau 2003). The category " 3,000 square feet or greater" was added only in 1988, so a longer historical trend cannot be provided, nor can an estimate of the number of "monster" houses surpassing $4,000 \mathrm{ft}^{2}$. The data are not aggregated at the state level, therefore, this study used the data for the Western census division that contains California. NAHB provides a similar summary: in 1970, 10\% of new homes were larger than $2,400 \mathrm{ft}^{2}$; whereas, in 2002-2003, 37\% were greater than 2003. The proportion of small houses declined even more dramatically over this period: in $1970,36 \%$ of new houses built were less than $1,200 \mathrm{ft}^{2}$; whereas in 2002-2003, only 5\% were less than $1,200 \mathrm{ft}^{2}$ (NAHB 2004, 11).

${ }^{24} \mathrm{Need}$, of course, is very subjective; its discursive role is one of making comparisons to accepted or assumed standards. Dom Nozzi attributes the "monster home" phenomenon to the United States as partly a result of a retreat into the private sphere ("The emergency of scape-offs and monster homes," http://user.gru.net/domz/scrape.htm.).
} 
This relationship is made clear in a National Resources Canada website, discussing the R2000 HOME program that is meant to deliver "energy-efficient and cost-effective" homes:

"Some R-2000 homes are modest in size, while others might qualify as "monster" homes. What they all have in common is a certificate that shows these houses meet stringent technical and quality requirements, and that they qualify as the most environmentally responsible housing to be found anywhere in the world." 25

The passage implies that environmental responsibility in housing is independent of house size and amenities "demanded" therein, so that a monster home can readily be given an environmental label. From a scientific standpoint, if responsibility is inversely proportional to "environmental footprint," the claim made is wrong: even modest-sized R-2000 houses will use considerably more resources that most dwellings in the world, especially multifamily units and dwellings in the developing world. Green buildings reflect a similar situation. It is a very big business. The National Association of Home Builders (NAHB) calls it "the most exciting and significant trend in home building in the past three decades" (NAHB 2004). However, despite what may be a good deal of "good intentions," in the end this is a marketable product. ${ }^{26}$ "Environmentally correct housing has never been more popular. But even the most eco-friendly home may do more harm than good when it is super-sized" (Baker 2004).

A common argument made by green designers when they defend their $10,000 \mathrm{ft}^{2}$ houses for wealthy clients is that if they were not designing green buildings, these houses would use even more energy and resources. This, indeed, is the standard argument for "efficient and big." Noted green architect, William McDonough, claims that his large house designs have generated local demand for certified wood products, and if he had not created a large house in the first place, there would not have been the demand for these items (Baker 2004). McDonough further observes that "if we go solar (PV), install rainwater catchment systems, use sustainably harvested lumber, why does it matter how big a house is? Nature is prolific (just look at cherry trees), as long as nothing is wasted, why not celebrate abundance." There is also the "trickle-down" theory that if wealthy people build green houses, then middle-income people will want green, too. If Martha Stewart goes green, will others follow? More importantly, can green be anything but a relatively category, used to rationalize consumption rather than to moderate absolute environmental impacts?

\footnotetext{
25 "High quality housing can be as individual as you are," Natural Resources Canada, accessed December 2004, http://oee.nrcan.gc.ca/english/media/articles newhomes mar00 high quality.cfm?PrintView=N\&Text=N .

${ }^{26}$ The NAHB pointedly notes, "Lacking unwarranted government intervention in the form of onerous regulations...the home building can continue to make great strides in [the green building] endeavor...." (NAHB 2004). The "greening" of market products in general has generated far less critical attention than it seems to warrant, in terms of delivering actual environmental benefits. See Dewar (1995) for an important analysis of green marketing in general.
} 
From the above quotations, it is clear that proponents of large green houses for wealthy clients justify these houses by referring to their energy efficient and renewable aspects, ignoring their total energy and material consumption. It may seem that this discussion is focusing too much on the green "spin" rather than on the nuts and bolts of everyday efficiency, but the symbolic, psychological, and social implications of these messages can be quite powerful. When people refer to a home as "green," or "energy-efficient," whether it is one that meets California's Title 24 energy code, ASHRAE Standard 90, LEED, or Energy Star, the symbolic message, or expectation, is that it is also (comparatively) "low-energy." This distinction is lost in the case of monster homes that are both energy efficient and consume large quantities of energy.

Why are we seeing an increase in house size? The short answer to the question of why people want larger and larger houses is that the United States is a culture, or a system, where generally, more (or at least bigger) is better. But there are other forces at work as well, including mortgage and tax structures, complex zoning requirements, real estate practices, and other factors that drive up house size (none of which can be separated from what people "want" nor necessarily from energy efficiency policy). The high turnover in single-family houses often drives the decision for larger houses, as resale value is often more important in deciding the number of bedrooms and bathrooms than the actual need of the current residents.

Mortgage banks often lock in large house sizes by requiring the value of the home to be three times the value of the land, according to Art Castle, executive vice president of the Home Builders Association of Kitsap County, Washington: "If you put a house outside of these perimeters, you create a market aberration ... A lot of lenders are unwilling to support smaller houses" (California Energy Circuit 2004). Home energy rating systems (HERS), and a California variant, California Home Energy Efficiency Rating Services (CHEERS), are used as measures of the energy efficiency of a home, scaled relative to the Model Energy Code (MEC). HERS evaluates space heating, space cooling, and water heating efficiency, i.e., it does not attempt to estimate all energy use in the home. The Energy Star Homes program bases their new home program on HERS, using a rating of 86 as the minimum level to qualify. ${ }^{27}$ However, one study found no relationship between HERS score and energy use (Stein 1997a,b). This comparison does not adjust for house services or size, but it is a case when an efficiency-like rating does not correlate with actual consumption. Stein suggests the possibility of a take-back effect: people may demand more energy services from their homes because it is energy efficient. This could happen whether or not the house is more efficient, i.e., on economic or psychological grounds, or both (i.e., labeling something as energy efficient may rationalize more use). ${ }^{28}$

\footnotetext{
${ }^{27}$ The program now also allows builders to meet criteria through "Builder Option Packages," a set of technological specifications that vary by climate zone (see http://www.energystar.gov/index.cfm?c=new homes.hm verification, accessed 22 June 2005). A HERS score of 80 is keyed to the MEC, with a score of 86 implying $30 \%$ less expected energy consumption for heating, cooling, and water heating than a score of 80 for a given house (each point above 80 implies 5\% less consumption).

${ }^{28}$ The prevalence of this behavior is unknown, but households may often be much less "rational" about their use of appliances and equipment, etc. than is assumed in economic theory (Mick and Fournier 1998).
} 
Stein found that CHEERS ratings for older homes over-predicted energy use by about $50 \%$ for the average house and $37 \%$ in aggregate, and under-predicted energy consumption in houses built in 1992 and later by $8 \%$ on average and $22 \%$ in aggregate.

A study by Prahl (2000) suggests that the HERS requires smaller houses to have higher levels of energy efficiency by component than for larger houses, in order to achieve the same HERS score as the larger house. He remarks, "While scores demonstrate the relative levels of efficiency across house sizes, the reality is that given the same envelope and mechanical system characteristics smaller houses inherently use less energy than larger houses for a given occupancy" (Prahl 2000). Holding domestic water heating efficiency constant, the study found that, for a sample house configuration in Pittsburgh, Pennsylvania, a house of 1,537 square feet would need to install a heater of AFUE 96\% to achieve a HERS score of nearly 86; whereas a 5,564 square foot house would require heating Annual Fuel Utilization Efficiency (AFUE) of only 80\%. ${ }^{29}$ Building a bigger house more efficiently will typically "save" more energy than building a smaller house more efficiently, but the larger house will still consume more. Furthermore, since smaller houses are generally priced lower and cost less to build than bigger houses, the investment required for energy efficiency becomes a larger proportion of construction costs. The authors do not suggest that efficiency ratings will lead a family who was going to buy a 1,537 square foot house to buy a 5,564 square foot house instead; however it plausibly creates or reinforces pressures that reward higher consumption, economically (e.g., through mortgage decisions) and socially. A similar study using CHEERS and typical California building practices may be worthwhile.

Acknowledging the fact that bigger houses in general lead to more consumption per household, some green-building rating programs have started to incorporate a matrix for house size. Like many green residential programs, Portland Gas and Electric's (PGE) Earth Advantage certification in Portland, Oregon, is based on a combination of required measures and additional points that can be earned for a home's green features. In 2003, Earth Advantage created four advanced levels of certification, two of which incorporate a matrix for house size. For example, under the new Earth Advantage Gold Environmental and Water Efficiency package, a 2,500 $\mathrm{ft}^{2}$ home needs to earn 50 more environmental responsibility or resource efficiency points than a 1,999-square-foot home in order to earn the same ranking (Baker 2004).

The Vermont Built Green (VBG) program, started in 2003 and is recognized as the most comprehensive program in the country, takes this idea one step further. To earn VBG certification, a home must meet 54 requirements and earn at least 100 points. Under this system, the easiest way to earn certification is to meet the minimum requirements and build a very small house. For example, a two-bedroom house earns 100 points if it is $1,000 \mathrm{ft}^{2}$, but only 25 points if it is $1,500 \mathrm{ft}^{2}$. By contrast, a four-bedroom house at $5,200 \mathrm{ft}^{2}$ loses 100 points, meaning that the house will have to earn 200 points - twice as many-for VBG certification (Baker 2004). The draft Leadership in Energy and

\footnotetext{
${ }^{29}$ Other parameters were varied as well, all toward lower efficiency levels in the bigger house. There are a number of degrees of freedom by which a given score can be achieved, so the heating AFUE comparison, in that sense, is an example.
} 
Environmental Design (LEED) for Homes follows a path similar to that taken in Vermont. Ann Edminster, the chair of the task group for the LEED for Homes noted that "The proposed standard recognized house size as an important element. But the draft will be voted on by the task group members, and anything that I say about the criteria may be reversed through balloting." "But we have developed draft criteria based on a reference house of 2,000 square feet. For every $10 \%$ increase in size over 2,000 square feet, you have $10 \%$ more environmental impact, so to be certified you would need $10 \%$ more points. There is a strong consensus that size matters." (Energy Design Update 2003).

\subsubsection{Residential Refrigerators as a Case Study}

Virtually every household in California has at least one refrigerator, and many have two or more (CEC 2004). ${ }^{30}$ Primary refrigerators in California residences, on average, consume about $800 \mathrm{kWh} /$ year, though a quarter of single-family households operate a second refrigerator. The estimated energy consumption in these second refrigerators is $1,245 \mathrm{kWh} /$ year, resulting in estimated refrigeration consumption in single-family houses of about 1,100 kWh/year (CEC 2004).

California pioneered refrigerator energy standards, enacting the first refrigerator energy standards in the United States in 1976. The California standards were tightened twice, in 1979 and 1987. California's standards were followed by nationwide standards, with the first NAECA refrigerator standards going into effect in 1990, and subsequently stricter standards coming into force in 1993 and 2001. ${ }^{31}$ The NAECA standards cover 18 categories of refrigerators and freezers, with standards defined for each category based on the sum of adjusted volume times a category-specific scalar plus a category-specific constant, e.g., to accommodate features such as through-the-door (TTD) ice makers (U.S. DOE 1997).

Reflecting these efforts, refrigerators are often promoted as one of the success stories of energy-efficiency policy (Deumling 2004). The EIA estimates that nationwide electricity consumption by refrigerators fell from 152TWh to 126Twh between 1992 and 1999, a rate of 2.2\% per year (Brown and Koomey 2003, 856, citing U.S. DOE 1995, 2000). However, other estimates of aggregate refrigerator consumption suggest that refrigerator energy use has increased over the long run, for example, at a 1.2\% annual rate of increase for California between 1975 and 1999 (Brown and Koomey 2003, 856-857), surpassing the state's population growth. And "although new refrigerators sold in the United States in 2001 consumed an average of $565 \mathrm{kWh} / \mathrm{yr}$, or roughly one-third of the 1972 average, ... the total primary energy dedicated to "standard-size" U.S. refrigerators is higher today than in 1974" (Deumling 2004, 15). What is more, Deumling notes, is that refrigerators sold in 1972 had dramatically higher consumption than those sold in the early 1960s, and

\footnotetext{
${ }^{30}$ Note that in some definitions of the refrigerator end use, various refrigeration equipment (e.g., compact refrigerators) are omitted.

31 "Appliance Efficiency Standards: A Great Untold Success Story of Energy Policy," by the Appliance Standards Awareness Project, http://www.standardsasap.org/refrigerator.htm, provides a summary of California and national refrigerator standards. See Turiel (1997) and Turiel, Chan, and McMahon (1997) for useful descriptions of standards policy and progress.
} 
the "refrigerator population" of 2001 consumed almost 5 times that of the refrigerator population in 1957 (Deumling 2004, 16, 21), obviously surpassing the corresponding population growth. Certainly refrigerators are far bigger today than in the late 1960s, and provide more services (e.g., TTD ice-makers), and consumption has grown far more than efficiency can or has overcome.

The federal refrigerator efficiency specifications are a good example of the challenges in balancing consumption with efficiency when it comes to size and features. Here, for example, are three efficiency specifications for refrigerator-freezers (AV stands for adjusted volume and the number following it is a constant, as explained below):

- Automatic defrost, side-mounted freezer, through-the-door ice maker: $10.10 \mathrm{AV}+$ 406

- Automatic defrost with bottom-mounted freezer: 4.60AV +459

- Refrigerator-freezer with partial automatic defrost: $8.82 \mathrm{AV}+248.4$

The equations define the maximum estimated energy consumption (in $\mathrm{kWh}$ ) allowed per year, under specific test and modeling procedures. There are two components to each equation, one component linearly scaling with product size (i.e., refrigerator-freezer volume), and the other a constant offset. Both the slope of the line (first component) and the size of the offset (second component) vary according to model category, as seen in the three examples. As to how these play out in total consumption allowed, consider a 20-cubic-foot refrigerator-freezer, a moderate size unit in the U.S. market today. A 20-cubic-foot refrigerator with partial auto-defrost freezer has a maximum annual consumption of $425 \mathrm{kWh} /$ year, the 20-cubic-foot bottom-mounted freezer has a maximum annual consumption of $551 \mathrm{kWh} /$ year, and the 20 -cubic-foot side-by-side with a TTD icemaker has a maximum annual consumption of $608 \mathrm{kWh} /$ year. The consumption limit for the side-by-side refrigerator with TTD icemaker is $43 \%$ greater than for a partial auto-defrost of the same volume. In fact, according to the equations, a two (2)-cubic-foot side-by-side with a TTD would have a consumption limit about the same as the 20 -cubic-foot plain refrigerator. ${ }^{32}$ The variety of categories for refrigerator-freezer leave room for variety in manufacturer and consumer choice, even as they may also shape or limit technological development. ${ }^{33}$ However, they provide no guidance for efficiency of design vis-à-vis usability (Jelsma 1999). More pointedly, they do nothing to mark or increase adoption of lower-consuming configurations. In fact, the side-by-side configuration may be becoming more popular. It is possible that such standards encourage inefficient configurations and additional features.

\footnotetext{
${ }^{32}$ Of course, this is in part a matter of how the equations are set up (intercept plus slope), and nobody expects to sell a 2-cubic foot side-by-side refrigerator.

33 The relationship between standards and technological design, technological trajectories, and innovation potential is a very important one, as standards can either constrain or spur development. These issues are out of the scope of our current analysis, but see Meier and Hill (1997) for some specific comments on energy test procedures and technological development vis-à-vis smart appliances. Another important issue is design with respect to usability and the overlap of design with efficiency standards, as discussed in the case of refrigerators (Jelsma 2001).
} 
A European study on potential revisions to European cold appliance standards pointedly noted this fact (European Commission 2000). The report recommended against giving a similar "bonus" for a TTD icemaker, for example, remarking that "giving a large fixed bonus to this feature might encourage its proliferation, and in particular, the development of much smaller TTD ice-dispensers, which use less incremental energy than the bonus" (European Commission 2000, 227). Manufacturers may even be driven to add TTD icemakers because of the bonus. ${ }^{34}$ The European report also provides a detailed technical analysis of the inefficiency of straight line efficiency standards - in this case, a standard specified by an intercept and a slope scaled for "energy services" (volume of refrigeration), which specify the optimum energy use for only one size, leaving "uncaptured" efficiency potential on either side. If the standard curved traced thermodynamic properties more closely, the savings represented by this gap could be gained at a price- or effort-levels roughly equivalent to that of the refrigerator for which the standard is ideal.

The common argument that "if not for efficiency, energy consumption would have been even greater" sidesteps what is at stake and relies on a self-constructed baseline by which efficiency is always successful. Doubtless efficiency often has and will continue to deliver great benefits (depending on the criteria used); however, as can be seen in the case of refrigerators, there is little evidence that energy efficiency has delivered absolute savings. Whether efficiency actually encourages consumption, rather than diminishes it, is perhaps more a philosophical question than one that can ever be "proven." One might argue that the efficiency gains have been "taken back" in the name of convenience.

From an energy perspective, a further question is whether home refrigeration is more or less energy-consumptive than the equivalent refrigeration in the supermarket, in the warehouse, or otherwise in the process of getting the food from producer to the consumer's home. There is no fixed need for a particular amount of refrigerated stuff. There is anecdotal evidence that the more space available in the refrigerator, the more things that "don't need to be in the refrigerator" will be put there. This phenomenon further raises a number of questions about what efficiency can do to reduce consumption. Deumling (2004) describes the situation with refrigerators as follows: "Technical insights gained in the course of eighty years of refrigerator design have not managed to offset the increased overall energy demand due to growth in the number of households. What makes absolute reductions difficult is the compatibility of energy efficiency programs and standards with continuing growth in refrigerator size, in the number of refrigerators per household, and in the average level of energy-consuming features."

Deumling (2004) notes as well that refrigerators of today use about as much as refrigerators of the 1960s. The 1960s was a period when the utilities commenced a sizable load-building effort, so that while energy efficiency did increase dramatically in step with the series of NAECA standards, the consumption baseline may be intentionally

\footnotetext{
${ }^{34}$ This is similar to critiques made of the Golden Carrot refrigerator award program (Moezzi 2000).
} 
inflated. Of course, load-building is almost as old as distributed electricity, but these stakes are often somewhat forgotten in energy efficiency rhetoric. ${ }^{35}$

\subsubsection{Air Conditioning as a Case Study}

Though the record is mixed, air conditioning appears to be a growing end use in California residences. ${ }^{36}$ By some accounts it is the second largest residential electrical end use (CEC 2004). Most single-family homes in California are built with central air conditioning. This technically builds in future load increase, particularly as residential construction has increasingly moved to the warmer interior of the state. Air conditioning is usually considered to be of predominant importance in peak load in contrast to baseload end uses, like refrigeration, but in terms of its total contribution to residential electricity consumption, air conditioning is clearly important as well. ${ }^{37}$ Table 2 summarizes current air conditioning patterns in California residences, according to the most recent RASS.

For the stock as a whole, about half (46\%) of single-family homes have central air conditioning, with an average estimated consumption of $1,423 \mathrm{kWh} /$ year based on data collected by IOUs (CEC 2003). Some $17 \%$ of the remaining single-family dwellings use either room air conditioning or evaporative cooling, with $12 \%$ using multiple systems

\footnotetext{
${ }^{35}$ See Herring (2006) for a summary of the development of the U.S. electric lighting market as a loadbuilding exercise in early twentieth century. Herring also provides a summary of the hybrid public lighting/electricity market in the U.K, showing how tremendous increases in efficiency have been more than matched by increases in lighting dependency.

${ }^{36}$ Certainly, conventional wisdom holds that air conditioning in California residential sector has been strongly increasing over the past 20 years, especially in the percentage of households with central air conditioners (CACs) and also in their propensity to use air conditioning, mirroring changes nationwide (see, e.g., EIA 1999). There appears to be little quantification backing these California trends, and what is available gives a mixed picture. The best information is probably the 2003 RASS, whose results strongly support increase in saturation: 78\% of single-family homes in California built after 1996 had central air conditioning, while only $41 \%$ of those built 1996 or earlier did (Tobiasson et al. 2004). Relying on somewhat older data, another analysis suggests that there has been very little growth in total electricity consumption for air conditioning, with 1999 total consumption just $0.4 \%$ above 1975 consumption (Brown and Koomey 2003). The authors attribute the lack of growth to the efficacy of Title 24 and of building standards; this is also an example where the uncertainty of the underlying data should be explicitly taken into account. Especially since new houses contribute relatively little to the total sector, depending on the timing of the dramatic increasing in air conditioning, the results may be consistent with the RASS results. In any case, according to the most recent RASS results, air conditioning is about $10 \%$ of California's residential electricity consumption, as compared to about $6.6 \%$ from somewhat earlier data (Brown and Koomey 2003, 855). It is unlikely that the trend to include CAC in new housing will stop of its own accord, because housing norms may have "permanently" been ratcheted up to expect central air conditioning. Thus, new load potential is being built in the new housing stock through air conditioning, with housing design tending to require operation of the CAC. Since air conditioning, over all sectors, contributes an estimated $40 \%$ to system peak, it is important from peak planning purposes, which is often the emphasis of CAC policy making (e.g., Springer 2003), but from an environmental standpoint, its estimated $10 \%-12 \%$ contribution to total residential electricity consumption is among the highest by end use. California passed stricter standards for residential central air conditioners, an exception to federal regulations.

${ }^{37}$ Brown and Koomey $(2003,854)$ estimate that air conditioning in California, including both commercial and residential sectors, contributes about $30 \%$ to peak load. The marginal environmental impact of cooling may be relatively high, to the extent that peak load presses older, more polluting, generation into service.
} 
(CEC 2004). The UEC for room air conditioning is about $20 \%$ that of central air conditioning. UEC for evaporative cooling is about $50 \%$ that for central air conditioning. Saturation is high in mobile homes (often located in desert zones, climatically the most suitable for evaporative cooling technology), but overall only a few percent.

Table 2. A summary of cooling end uses in California residences served by California IOUs, based on the Residential Appliance Saturation Survey

\begin{tabular}{|l|c|c|c|c|c|c|}
\hline \multirow{2}{*}{ House Type } & \multicolumn{2}{|c|}{$\begin{array}{c}\text { Central Air } \\
\text { Conditioner }\end{array}$} & \multicolumn{2}{c|}{ Room Air Conditioner } & \multicolumn{2}{c|}{$\begin{array}{c}\text { Central Evaporative } \\
\text { System }\end{array}$} \\
\cline { 2 - 7 } & $\begin{array}{c}\text { UEC } \\
(\mathrm{kWh} / \mathrm{yr})\end{array}$ & $\begin{array}{c}\text { Saturation } \\
(\%)\end{array}$ & $\begin{array}{c}\text { UEC } \\
(\mathrm{kWh} / \mathrm{yr})\end{array}$ & $\begin{array}{c}\text { Saturation } \\
(\%)\end{array}$ & $\begin{array}{c}\text { UEC } \\
(\mathrm{kWh} / \mathrm{yr})\end{array}$ & $\begin{array}{c}\text { Saturation } \\
(\%)\end{array}$ \\
\hline $\begin{array}{l}\text { Single-Family } \\
\text { Detached }\end{array}$ & 1423 & 0.46 & 277 & 0.15 & 688 & 0.05 \\
\hline $\begin{array}{l}\text { Single-Family } \\
\text { Attached }\end{array}$ & 713 & 0.41 & 148 & 0.14 & 595 & 0.02 \\
\hline Mobile Home & 1143 & 0.39 & 227 & 0.34 & 537 & 0.27 \\
\hline $\begin{array}{l}\text { Multi-family } \\
\text { 2-4/units }\end{array}$ & 1019 & 0.28 & 120 & 0.16 & 374 & 0.02 \\
\hline $\begin{array}{l}\text { Multi-family 5+ } \\
\text { units }\end{array}$ & 749 & 0.32 & 105 & 0.22 & 403 & 0.02 \\
\hline
\end{tabular}

Source: CEC 2004

From the perspective of growth in electricity consumption, air conditioning is an interesting end use. It contributes moderately to overall consumption but even more substantially and unpredictability to peak load. It also delivers more than cool air (humidity control and sometimes heating), and it is also a relatively recent "must have" end use in California, one that has transcended the luxury category to become perceived as normal within the past 25 years - the same period that might be considered the era of energy efficiency. There was nothing inevitable about this transformation, in the sense of autonomous technological change. Instead, it was the result of a number of social and technological changes and choices. Air conditioning has made California residents more comfortable than they would have been otherwise; however, within broad limits, comfort is at least as much a psychological notion as it is an absolute physiological notion (Crowley 1999; Shove 2003).

Technical specifications of what constitutes a comfortable environment for humans are inevitably linked to the availability of technologies that can deliver this comfort, These shifts operate along several dimensions. First, residential building practices have changed not only to accommodate central air conditioning, but also to make central air conditioning necessary for the adequate functioning of the building (Cooper 1998). The growth in the use of residential air conditioning cannot be well understood without acknowledging the active interest of industry in building air conditioner sales and corresponding electrical load (Ackermann 2002; Cooper 1998). Second, social standards change toward requiring air conditioning as well. These shifting requirements are reflected in, and by, various forces of the residential market, such as mortgage rules and housing prices, the panoply of which renders lack of air conditioning deviant (Hungerford 2004). 
Energy efficiency policy itself creates and plays by these social rules. By rewarding efficiency in CAC purchase, policies may also reward and encourage air conditioning itself. Some research based on southern California programs has suggested, for example, that utility rebates offered for the adoption of high efficiency central air conditioning may in fact encourage the adoption of air conditioning among customers who previously did not have air conditioning (Samiullah, Hungerford, and Kandel 2002). Thus, rather than reduce air conditioning consumption courtesy of increased efficiency, bonuses or rebates for new efficient air conditioning may increase air conditioning consumption overall. There are not only direct effects but indirect effects as well: "Such incentives may be helping to solidify the perception that compressor-driven central air conditioning is normal, standard, and environmentally benign, as long as it's efficient" (Samiullah, Hungerford, Kandel 2002). By this token, energy efficiency programs can normalize and thus sponsor, technically and socially, additional, albeit technically efficient, consumption. By including less energy-intensive cooling alternatives as options in programs, some of this effect can be offset (Samiullah, Hungerford, and Kandel 2002). Thus, category definitions may constrain the development and adoption of alternative technologies that provide a similar end use service for lower environmental impact.

Voluntary programs are generally faced with marketing energy efficiency, which arguably leads to rather exaggerated and feel-good claims. The most familiar and widespread energy efficiency program in the United States is the Energy Star program. It is only in a very relative, sometimes even ironic, sense that efficient central air conditioning "saves the planet" - a term that is often used to urge consumers to buy more efficient goods. Market-centric voluntary programs, by nature, may tend to legitimize the installation of central air conditioning as environmentally beneficial. This might be seen as an elaboration of the rebound effect argument: not only does efficiency make air conditioning cheaper, it can also "create" the end use in itself. ${ }^{38}$ For the case of new construction, the efficiency of houses with air conditioning is compared only to standards that also assume air conditioning, so that the end use itself is left as a need, not subject to environmental questions.

From the policy perspective, this is a classic dilemma. Energy efficiency policy can hardly ignore central air conditioners altogether, given their importance to peak and the range of efficiencies for CACs available in the market. Yet, with the arguable exception of regulatory standards, policy that promotes efficient central air conditioning promotes central air conditioning itself. Furthermore, energy policy inevitably concentrates at the point of purchase, since downstream use is very difficult to address. With attention focused on making an efficient purchase, the installation and use of the equipment is deemphasized. This situation is particularly important for air conditioning, since the electricity consumption from air conditioning is so strongly influenced by consumer

\footnotetext{
${ }^{38}$ Furthermore, residential customers may be largely unaware of what their air conditioning costs; they may over- or under-estimate these costs. Though the attentive can readily gather some estimate, for many, air conditioning costs are just part of a monthly total, which itself may not be of interest or in many cases may not even reflect a specific month's consumption (e.g., for those on flat-billing option).
} 
behavior (e.g., how the air conditioner is operated and when) and by design, maintenance, and installation (Wray and Sherman 2001). These technical problems include oversizing, duct sealing, building envelope sealing, insulation and air barrier installation, and overcharging.

Our responses to this situation remain at the stage of questions. Room air conditioners and evaporative cooling have far lower UECs than for central air conditioning, as summarized in Table 2 above. This difference is in part because central air conditioning is the more likely choice for higher-load situations (i.e., it is the technology of choice for bigger dwellings and for dwellings in hotter climates). The question remains as to the extent that alternative, lower consuming, technologies can substitute for central air conditioning, a problem considered in some depth in a California study on compressorless cooling (Hungerford 2004). To the extent that efficiency policy rewards efficient central air conditioning, it dis-incentivizes the development of alternatives to central air conditioning, whether mechanical, architectural, or social. How can these disincentives be overcome? How might codes be written so that "efficient" central air conditioning is not defined on the basis of "standard" central air conditioning, but instead better incorporate other cooling choices? Are air-conditioner standards developed nationwide applicable to California, and if not, what are the effects of national air conditioner standards?

California has conducted innovative work on residential cooling. For example, the state undertook a multiyear research effort to develop and market houses without compressorbased air conditioning, These houses, located in "transitional climates," relied on smart siting, shading, traditional design element and other strategies to eliminate the need for central air conditioning (Loisos and Ubbelohde 1998). By redefining the service of "cooling," the focus was shifted from improving the efficiency of equipment to an alternative strategy that used far less energy. 


\subsection{Policy Considerations, Technical Possibilities, and Recommendations}

What all three of these case studies have illustrated are some of the challenges of using energy efficiency for crafting effective policy for reducing energy use and carbon emissions. The next section looks at the options for policy, and notes the strengths and limitations of energy efficiency as a tool for this endeavor. The policy discussion is separated into three parts. Section 4.1 re-evaluates some of issues raised in the introduction, in light of the potential of policy to overcome these problems. Section 4.2 summarizes options for relatively technical aspects of efficiency definitions, along with some general recommendations for policy. Section 4.3 suggests a number of questions for further research and discussion by the energy policy community.

\subsection{Policy Considerations}

"Societies learn and yet the world is hard to change," Klaus Elder says (Elder 1999). Energy efficiency policy has succeeded in making houses, and their contents, more efficient. Yet other changes have entered the equation, and these changes have challenged efficiency's apparent contributions to environmental impact reduction. Increases in technological efficiency has not lead to more efficient living (e.g., less energy per individual). The extent to which policy could have done better, and within what conceptual framework, is uncertain, but policy itself is a product of society. This analysis has carefully distinguished problem from solution. Otherwise, analysis threatens to slip too quickly into policy response-mode, "what can we do," which often produces results and solutions, often short-term and countable rather than long-term and possibly more effective. And policy recommendations coming from political outsiders can be hopelessly utopian or idealistic.

If policy is to address the environmental effects of consumption more effectively, it must come to terms with what may be a core conflict between environment and economic growth. In the energy field, energy efficiency has appeared to offer a perfect solution, a "win-win-win" that delivers tables of fiscal savings as well as millions of acres of virtual trees planted. From the standpoint of the historical development of the energy efficiency field, energy efficiency was an existing solution that appeared to meet the needs of environmental protection. No doubt that it can do this very well in some cases. However, just because nearly everything can be made more energy efficient does not make it a generally satisfactory environmental solution, and as a metric for the environmental impacts of energy use, efficiency is imprecise and possibly counterproductive.

In summarizing problems of the "marketability" of environmental policies, Jackson and Michaelis write:

The current institutional consensus has tended to settle for a position that implies consuming differently rather than consuming less, and in which this is to be achieved primarily by the production and sale of more sustainable products. This position is problematic because it collapses the distinction between sustainable consumption and sustainable production. It also fails to address important 
questions about the scale of consumption, the nature of consumer behaviour, and the relevance of lifestyle change. (Jackson and Michaelis 2003)

The question of consumption is hidden from policy view, treated rhetorically as a moral issue, but outside the boundaries of normal environmental policy, which concentrates in the realm of sustainable production. Energy efficiency itself demonstrates the concentration on production quite well, since it serves to efficiently produce energy services.

Energy efficiency does have some special characteristics distinct from those of the consumption of material goods. For one, energy efficiency concerns only the expected energy used by a product, and leaves out, from the sustainability equation, the question of the environmental impacts of the product (e.g., the air conditioner) and the nominal service it provides (i.e., air conditioning). These are taken as given. ${ }^{39}$

The reluctance to question consumption has obvious appeal. As Jackson and Michaelis write about sustainable consumption in general:

Institutional reluctance to address these latter issues appears to hinge on three concerns. In the first place, addressing them properly would involve questioning fundamental assumptions about the way modern society functions. In the second place, any attempt to address consumption quickly becomes reflexive and challenges us at the level of personal change. Finally, questioning consumption appears to threaten a wide variety of vested interests. (Jackson and Michaelis 2003, 4)

Rather than go into a discussion of the absolute ills of consumption, analyses should focus on the narrower point of what efficiency-technically, economically, psychologically, and socially - does (or might do) to curb (or not curb) the environmental impacts of energy consumption.

In the tension between efficiency and consumption, policy faces a core conflict. In general, the environmental damages of energy consumption are proportional to energy consumption. Moreover, it is considered politically impossible to put into place policies that would reduce consumption. Energy efficiency seems to offer a solution, since it appears to reduce energy consumption (documented in charts and tables), while leaving "consumption" on the whole untouched and, for the most part, increasing economic productivity. And because such a solution is so welcome, this central conflict faced by the energy efficiency policy community remains virtually untouched by serious, open, discussion.

Given the social, cultural, and political-economic realities, how well any foreseeable energy efficiency policy can successfully reduce energy carbon emissions is an open question. For example, there seems little point in moral arguments that Californians

\footnotetext{
${ }^{39}$ Furthermore, their calculated savings are "futures" on the purchase, estimates of what might be used by the product, generally based on weak information.
} 
consume too much and ought to consume less, or correspondingly, for making a central recommendation that policy exhort people to consume less. However, several options for policy exist, based both on literature review and our own findings. The first set of suggestions concern changing technical definitions of efficiency and the forms these changes might take. Following this are listed a number of process-oriented suggestions for policy and policy-research.

Above, it was suggested that the notion of "efficiency" may ideologically be antagonist to absolute reductions in energy consumption, at least in aggregate. However, the notion of energy efficiency is flexible. When viewed at a micro-level (i.e., at the level of individual measures), "efficiency" may be reworked to better capture technical potential for increased efficiency or energy consumption. When viewed at a societal level, efficiency may permit a systems-level thinking that is logically and technically amenable with reducing absolute levels in energy consumption. For example, one might think of efficiency as "energy utilized per person" (i.e., the "service" provided to maintain one person), which is more in line with a "footprint" perspective on consumption. Even with revisions, efficiency itself may have fundamental limitations in addressing consumption, as noted above, but it can be made incrementally more effective without major upheaval. One of the reasons that energy efficiency has been defined as it has is because there is a need for policies and specifications that are tractable in practice, avoiding both overly detailed specifications, and avoiding questions that step too far into the realm of philosophical, social, and moral debate. Some progress can be had if policy and evaluation can find a way to shift from over-reliance on numeric proofs emphasizing success to broader types of discussion and evaluation.

\subsection{Options for Instruments}

This study's case studies and literature review suggest a few possible technical approaches for adding or reconfiguring policy instruments by which efficiency might be recast to reduce consumption. These are logical possibilities, rather than the authors' recommendations, though some assessment of each is offered. These approaches include the following:

- Non-linear definitions of efficiency. In principle, it is often easier to make larger things more energy efficient than smaller ones, insofar as energy efficiency is defined linearly in terms of size. It has been suggested, by the authors as well as others (e.g., Meier 2000), that a tightening of the curve toward bigger sizes-e.g., less extra energy allowed per unit of increased size or service-would help capture some of this potential. This is partly a matter of thermodynamics, as well as the extra flexibility provided by having more space to work with. This is enhanced by social and economic factors, since bigger goods typically have more options installed (e.g., refrigerators and houses) and usually cost more, so adding extra efficiency may be inexpensive relative to total cost or price to consumer. For example, as noted above, building energy efficiency is often described in terms of (modeled) energy consumption per square foot, and refrigerators energy efficiency is conventionally defined, within predefined categories of refrigerators, in terms of expected energy consumption per adjusted unit volume, along with 
consumption credits for added features, as some of the house efficiency options described above address. These could be read as "penalties for size," but they can be more positively construed as taking advantage of particularly favorable social and technological opportunities. ${ }^{40}$ Technically, the savings from such adjusted guidelines may be small, especially relative to the burden of complexity added. However, guidelines could obviously be made increasingly strict or severe, the limits being social, political, or economic, rather than technological. These stricter limits might have two direct effects: making bigger things more efficient and less consumptive than they would have been under linear definitions of efficiency; and creating downward pressure on the size of things eventually constructed, rather than the upward pressure that linear efficiency or "bonuses for features" create. There is an important side effect: stricter standards for bigger things can send a social message that consumption is not environmentally free. Of course, it repeats the aforementioned problem of associating efficiency with bigger (and depending on the severity of the guidelines, still generally higherconsuming) goods. Nevertheless, this attention to size and overall consumption seems overwhelmingly positive, as our recommendations below reflect.

- Feature creep: Care in how consumption allowances are set. Larger, typically more expensive, products tend to have more features added, over and above basic functionality, than do smaller, less expensive, products. ${ }^{41}$ In general, these features are first seen on higher-end products, which are also the most amenable to market-based energy efficiency programs, notably Energy Star. Ironically, such higher-end products often use more energy than "standard" products, both because of their bigger size and because of added features. In general, marketoriented products need complex policy. However, complex policy may create loopholes by which the intention of the policy is bypassed. Moreover, they may even lead to the proliferation of energy-consuming features (European Commission 2000), whereby efficiency guidelines potentially create leverage toward higher consumption.

- Categories and end uses. Energy policies are predominantly focused at the level of end uses defined by a particular technology, and often a particular feature set within that technology: e.g., particular size and configuration of refrigerator rather than refrigeration, or central air conditioners rather than cooling. This connects efficiency very closely to technological configurations, and there are practical reasons for doing so. However, efficiency could also be defined at a higher, more aggregate level, such as the provision of cooling or the provision of residential space. A broader concept of end use service can offer much more flexibility in attaining efficiency; in general, the higher the aggregation of end use service, the

\footnotetext{
${ }^{40}$ The question of what is "particularly favorable" depends on the conceptual model used and the assumption therein. If one considers it from the standpoint of societal efficiency, seeking those niches in which technical efficiency can be most inexpensively gained, larger goods or right-sizing are probably among the most favorable candidates.

${ }^{41}$ Portable electronics are an exception, with smaller goods (e.g., portable telephones, PDAs, audio devices) generally at a premium.
} 
more opportunities offered. By broadening end use categories utilized in policy, it may be possible to create space for technical innovation and to give "efficiency" credit to less-consumptive technological alternatives (e.g., cooling, rather than air conditioning).

- Energy consumption caps on what can be called efficient. Limits on energy consumption could restrict what products could be called efficient. For example, refrigerators would have to meet current efficiency standards, but no refrigerator greater than some limit (e.g., $700 \mathrm{kWh}$ ) could be sold as efficient.

- Carbon emissions permits or caps. Under such a scheme, each individual would be allocated an allowable amount of carbon emissions per annum; emissions credits could be traded (Fawcett 2003). This is based on absolute emissions and, therefore, if it worked, would limit total emissions outside of that stimulated by population growth. The authors do not raise this to advocate it - among other things, it seems politically infeasible, at least at the moment, and could find its own way to circumvent intentions - but it remains an important idea conceptually.

\subsection{Recommended Policy Directions}

There are powerful forces that have shaped current energy use policy to its current form. Among these are a capitalist economy, deeply held beliefs about the power of technology to inevitably produce solutions, a need to offer politically palatable programs and research, and in general, deeply held American traditions. The authors want to avoid suggesting utopian solutions of the sort that cannot be implemented within this context, without giving up the idea of improvement. Thus, our policy recommendations focus on identifying questions and directions that the energy policy research community might tackle together.

- Consider integrating absolute consumption into technical and political definitions of efficiency. Depending on the end use, a variety of approaches should be considered to better track absolute consumption, rather than relative notions of consumption. These include: (a) designing increasingly stringent energy-efficiency requirements for larger goods; (b) placing absolute limits on consumption allowed for a particular good to be promoted as "efficient", and (c) making comparisons across a broader range of technologies and practices, rather than focusing down to a specific end use (e.g., "cooling" as a category, rather than "central air conditioning"). Because of the political and multidimensional technical complexity of energy efficiency specifications, and the project's limitations, the authors do not offer detailed examples. A general recommendation is to ensure that policy explicitly integrates total consumption into standard definitions, program structures, and other policy procedures. As to savings calculations, energy efficiency definitions routinely allow what amounts to consumption credits for greater size or extra features, whereby such definitions may ironically even encourage increased size or features and thus lead to increased energy use and GHG emissions. To help overcome this effect, careful 
attention should be paid to the construction and reporting of the baseline relative to which savings are calculated.

- Attend to the social messages of energy efficiency communications. There may be perverse psychological effects of "selling" energy efficiency to consumers. Efficiency is routinely promoted as the choice that is good both for the economy and the environment. This message dominates both at the aggregate level of national economy as well as at the level of individual consumer choice. For the latter, efficiency is routinely credited, whether by government programs or by commercial or other enterprises, with "saving you money, while saving the environment." The alternative of "conservation," often pitted against efficiency, is characterized as sacrifice (Moezzi 2000). The distinction drawn between environmental propriety and sacrifice reflects, and communicates, the notion that consumption is the rational environmental solution. Programs often associate environmentalism with higher energy-consuming and often higher-priced products, thus creating another positive association between high efficiency and increased consumption, even while appearing to offer frugality and lower consumption. While advocating sacrifice may be ineffective outside of times of crisis, denigrating conservation as a violation of "right to consume" creates a psychological current that may be contrary to environmental goals. If environmental protection is the goal, focusing only on narrow definitions of relative savings diverts attention and effort away from much more important environmental issues.

- Broaden the definition of "environment" in stating the costs of energy use and the benefits of energy efficiency. Carbon emissions have become the metric of environmental damage caused by energy consumption, to the virtual exclusion of recognizing many other environmental damages resulting from energy consumption. These damages include direct pollution from electricity generation, as well as damages resulting from the production of energy-using devices. These other damages should be considered as well, toward a more holistic and effective basis for environmental protection. An environmental externalities framework provides one possible route for doing so.

- Make sure the information given to consumers is good and fair. Providing simple, general advice to consumers to motivate them to invest in energy efficiency may be ill-founded (Diamond and Moezzi 2000), stated over-precisely (e.g., offering precise savings estimates or cost-benefit ratios, derived from oftenoptimistic models applicable to "average" cases), misleading (e.g., expressing savings from energy efficiency in terms of "number of cars taken off the road," when no cars are actually taken off the road), or without sufficient qualifying conditions. Few general statements about the world can be precisely true; in the case of energy efficiency, this problem is due to the variability of energy consumption and lack of information. This leaves those who are charged with marketing campaigns, in any environmental field, in a quandary. The ethics of energy efficiency campaigns, especially those launched by governments, should 
stand on their own right. A critical review of industry practices and traditions for providing energy advice or savings claims is in order. A process for ensuring factchecking, broadly defined, could help alleviate these problems, even if statements made outside of government offices cannot be readily controlled.

- Pay more attention to data, data quality, uncertainty, and trends. The energy policy research field is filled with numbers, many of which are prepared with great care. However, there are serious but addressable shortcomings in data and its treatment, relative to the quality of the answers given to the questions the field sets itself to address. Uncertainty is rarely formally assessed or acknowledged, and model estimates are too often taken as real data. A comprehensive assessment of data availability, data needs, and the potential value (e.g., in advancing scientific knowledge or answering policy questions) of improvements in the data inventory would be of great use.

- Develop a more open, critical, perspective on the benefits and limitations of energy policy and the assumptions on which they are based. The fundamental dilemma of U.S. energy efficiency policy for achieving environmental goals is that of moderating consumption while convincingly supporting economic growth. These goals may largely conflict, yet the conflict is generally denied or ignored, rather than addressed head on. The field is inevitably oriented towards demonstrating success and future potential, due to deep convictions of what is valuable (energy efficiency) and the need to protect research funding. Consequently, unintended consequences and outright failures are sublimated rather than analyzed, and idealism often takes precedence over what actually is occurring. The insularity of the field was noted long ago (Nader 1981). Uncertainty and assumptions are routinely under-acknowledged, leading to the impression that results in the field are more solid than they actually are, statistically. The authors advocate that conflicts between GDP and environmental protection need to be openly discussed, that evaluation seeks better ways to recognize and build from failures, that uncertainties be better identified and acknowledged, and that, in general, the field develops an ability to broaden the terms of discussion and debate.

\subsection{Recommendations for Further Research}

Because this was an exploratory project, this report has raised more questions than it has answered, leading to the following recommendations for further study or development. This is not an exhaustive list, but highlights areas where additional investigations are warranted to further understanding and ability to address issues relating to energy efficiency and environmental impacts.

1. What are useful or appropriate boundaries for efficiency definitions and efficiency analyses? For example, in the case of refrigerators, what are the limitations of the current practice of using the volume, configuration, and feature set of the refrigerator? What about the larger category of all refrigerators and the need for refrigeration (looking at the whole cycle of food production, consumption, and 
storage)? Can the community develop practices so that broader notions of efficiency and environmental impacts are better identified and considered? There is a need to develop some further examples, whether observed or theoretical, of how consumption might be better integrated into efficiency definitions.

2. What are the trends in energy consumption and electricity utilization, and what is behind (statistically/analytically, as well as sociologically/technologically) the differences? How could growing aggregate consumption be addressed through policy? Should policy address consumption? What are the political constraints about research on reducing GDP and consumption? How can the field acknowledge these tensions more openly?

3. How can the disciplines of psychology, sociology, anthropology, marketing, and social studies of technology give us a better understanding of how energy efficiency and consumption are related, getting beyond the economic summaries such as "take back" and "market barriers"? These models are useful at times, but they do not match real world experiences very well, not even for those who are in the energy efficiency field. ${ }^{42}$ Answering such questions entail, in part, relinquishing the equation of "consumers" with "people," and thinking more about what people do (other than what they buy). How can insights gained be effectively communicated and effectively bring any necessary shifts in policy direction?

4. What are the broader relationships between energy efficiency, consumption, carbon emissions and environmental damage? Can we develop better physical or economic summaries of the environmental damages of various modes of energy consumption, and use these to develop economic or social instruments that better internalize damage? What are the relationships between efficiency, population, affluence and technology? Can we have economic growth that is less harmful for the environment, or is growth inevitably linked to increased consumption and, on average, increased damage to the environment?

5. What are the connotations of such common terms as energy efficiency, conservation, energy savings, consumption, take back, market barriers, market transformation, and others by different disciplines, and how do these meaning inform or constrain policy? For example, the term "take back" suggests that the "lost savings" are somehow real, while in fact, they are merely projections based on a series of assumptions, and the explicit construction of conservation as sacrifice seems to force environmental protection to concentrate only on technological and consumption-enhancing solutions.

6. What are the trends, both national and in California, for the growth in house and appliance size? There is aggregate data from RECS, NAHB, and American Housing Survey (AHS) data, but it is hard to see the detail to know what is happening at the micro level, and how well these patterns can be ascertained.

\footnotetext{
${ }^{42}$ Golove and Eto (1996) Shove (1998) provide good critiques of the "market barriers" concept.
} 
7. What are the relative impacts of tax policies, mortgage practices, lenders, real estate agents, banks, building codes, etc., on the increasing size of houses? How do these factors vary regionally? More importantly, how might policies counterbalance these pressures?

8. How can we address the scarcity and limitations of energy data? What is the data situation for energy analysis (strengths and limitations): how much do we know, how well do we know it, and what data do we need in order to answer the questions we set out answer, or conversely, what investigations can be validly pursued with the data we have? Would a data clearinghouse help? What models are available to collect, organize, and make accessible the dispersed literature on energy?

9. Can we develop a system of review for information aimed at consumers that can be evaluated, and in which claims about efficiency can be assessed for accuracy, and social and psychological messages analyzed for consistency with overall needs?

10. What are the most effective mechanisms for conducting and continuing the debate on how to better critique the role, limitations, and assumptions of energy efficiency? What formats, approaches, and media, would best allow for a frank and open exchange of ideas? How can we build in mechanisms that allow for "fact checking," probing of assumptions, and questioning data and models? What assumptions are made, where, and how can we make these assumptions, and their change over time, clear? Could making the field's literature more accessible (e.g., by making all the ACEEE summer study proceedings freely available online, or by providing access to bibliographic resources that include published and gray literature) help build debate within the field and help invite support from outside? A book, such as a handbook or high-level textbook, that reviews the history of energy efficiency, critically analyzes assumptions, consumption trends, policy trends, past "failures" of energy efficiency (e.g., technologies that were disliked or did not work, problematic test procedures), clever successes, overlap with supply questions, comparisons with "efficiency" in other countries, and more, with a strong bibliography, might be a particularly valuable starting point. 


\subsection{Conclusions}

The fundamental environmental problem being addressed here is one of consumption. The trend towards bigger houses, with more appliances and energy services, more of which are "always on," not only represents an increase in material consumption, but represents a significant percentage of the state's electricity used to heat, cool, and operate them. While the shift away from conservation towards efficiency has led to significant improvements in the nominal efficiency of homes and appliances in the United States and California, energy consumption per capita has increased in a way that (from the perspective of absolute emissions reductions) conventional definitions of efficiency have not been able to adequately capture.

This report has argued that energy efficiency policy is not sufficiently oriented to consumption reduction to support the spirit or the content of environmental claims made for energy efficiency. There are serious obstacles to moving towards energy policies that reduce consumption. These obstacles are both political and sociological, though they are also manifested through scientific and technical constructs. At core, efficiency measures only relative consumption - and that at a highly disaggregate level. As a basis for energy policy, efficiency has not resulted in reductions in absolute consumption overall. By staying within the politically viable framework of "efficiency," but orienting efficiency to better reflect consumption, we may be able to simultaneously negotiate the political, sociological, and technical barriers to addressing consumption and environmental damage.

Overall, this work has focused on how energy efficiency misses its mark with respect to the reducing environmental impacts, as reflected in the following passage:

The real environmental risk is not that services will be redefined (this happens all the time), but that there will be sweeping cross-cultural changes in what people take to be normal ways of life, and a consequent locking in of demand for the resources on which these ways depend....Rather than promoting energy- and resource-efficient versions of products and technologies that inadvertently sustain unsustainable concepts of services, environmentalists should argue for social and cultural diversity. They should do all that can be done to engender multiple meanings of comfort, diverse conventions of cleanliness and forms of social order less reliant on individual modes of co-ordination. (Shove 2003)

The authors have several remarks on this passage, with respect to California. At a recent conference, it was suggested that rather than have developing countries learn "how to be efficient" from the United States, the United States might learn from other countries how to have lower energy-intensive lifestyles. ${ }^{43}$ If California could possibly unlearn some of its consumptive lifestyles - and document this unlearning - this would produce a revolutionary shift. Rather than focusing on the efficiency of end-use technologies, this would shift attention to the efficiency of the economy (Nørgård 2005). As to the second part of the passage, it suggests the limitations of spreading "efficiency" to all products

${ }^{43}$ A remark by Jaap Jelsma at the 2004 ACEEE Summer Study on Energy Efficiency in Buildings. 
and services. A revised notion of efficiency that captures absolute consumption better may escape part of this limitation. As stated previously, in summing up the "savings" from such specification, the total difference may be relatively small and retains an enduse focus. However, the indirect effects of this debate, such as drawing attention more to consumption, rather than linear notions of efficiency, may be substantial. 


\subsection{References}

Ackermann, Marsha. 2002. Cool Comfort: America's Romance with Air-Conditioning. Washington, D.C.: Smithsonian Books.

Baker, Linda. 2004. “Great Big Green Monster Mansions.” Salon.com July 7, 2004. http://archive.salon.com/tech/feature/2004/07/07/green_big_houses/index.html.

Bin, Shui, and Hadi Dowlatabadi. 2005. "Consumer Lifestyle Approach to US Energy Use and the Related $\mathrm{CO}_{2}$ Emissions.” Energy Policy 33:197-208.

Bromley, D. W. 1990. "The Ideology of Efficiency: Searching for a Theory of Policy Analysis." Journal of Environmental Economics and Management 19:86-107.

Brown, Richard, and J. Koomey. 2003. "Electricity Use in California: Past Trends and Present Usage." Energy Policy 31:849-864.

California Department of Finance. 2004. California Statistical Abstract 2004. Accessed from http://www.dof.ca.gov/HTML/FS DATA/STAT-ABS/Sa home.htm.

California Energy Circuit. August 13, 2004. "Livin' Large Causes Demand to Surge in Inland Empire."

California Energy Commission. 2002. California Energy Consumption by Sector. www.energy.ca.gov/electricity/consumption_by sector.html.

California Energy Commission. 2003. Appliance Efficiency Regulations. April 2003. P400-93016. www.energy.ca.gov/reports/2003-07-10 400-03-016.PDF.

California Energy Commission. 2003. "Climate Change Programs: An Overview." Commissioner James D. Boyd, May 12, 2003, at the Conference of the Reducers, The Hague. Placed online: May 29, 2003. http://www.energy.ca.gov/papers/2003-05-12_BOYD HAGUE.PPT.

California Energy Commission Consultant Report. 2004. California Residential Appliance Saturation Study. Final Report. June 2004. 400-04-009. Accessed from http://www.energy.ca.gov/reports/400-04-009/2004-08-17 400-04-009ALL.PDF.

Callon, Michel. 1998. "An Essay on Framing and Overflowing: Economic Externalities Revisited by Sociology." pp. 244-260 in Michel Callon, ed., The Laws of the Markets. Oxford, U.K. and Malden, Massachusetts: Blackwell Publishers/Sociological Review.

Chappells, H., and Shove, E. 2004. Comfort: A Review of Philosophies and Paradigms. www.comp.lancs.ac.uk/sociology/research/projects/futcom/fc litfinall.pdf.

Cooper, Gail. 1998. Air-Conditioning America. Baltimore: Johns Hopkins University Press.

Cross, Gary. 2000. An All-Consuming Century: Why Consumerism Won in Modern America. New York: Columbia University Press. 
Crowley, John E. 1999. "The Sensibility of Comfort." American Historical Review 104 (3). http://www.historycooperative.org/cgi-

bin/justtop.cgi?act=justtop\&url=http://www.historycooperative.org/journals/ahr/104.3/ah000749. $\underline{\mathrm{html}}$.

Deumling, Reuben. 2004. "Thinking Outside of the Refrigerator: Shutting Down Power Plants with NAECA?" In the Proceedings of the 2004 Summer Study for Energy Efficiency in Buildings. Washington, D.C.: ACEEE.

Dewar, Elaine. 1995. Cloak of Green. Toronto, Ontario: Lorimar \& Co.

Diamond, Rick, and Mithra Moezzi. 2000. "Revealing myths about people, energy and buildings." In Proceedings of the 2000 Summer Study on Energy Efficiency in Buildings. American Council for an Energy Efficient Economy. Washington, D.C. August.

Diamond, Rick, and Mithra Moezzi. 2002. "Becoming Allies: Combining Social Science and Technological Perspectives to Improve Energy Research and Policy Making." In Proceedings of the 2002 Summer Study on Energy Efficiency in Buildings. American Council for an Energy Efficient Economy. Washington, D.C. August.

Diamond, Rick, and M. Moezzi. 2004. "Changing Trends." In Proceedings of the 2004 Summer Study on Energy Efficiency in Buildings. American Council for an Energy Efficient Economy. Washington, D.C.

Elder, Klaus. 1999. "Societies Learn and Yet the World Is Hard to Change." European Journal of Social Theory 2 (2): 195-215.

Energy Design Update. March 2003. “Grappling With National Green Standards.” Energy Design Update 23 (3).

Energy Information Administration (EIA). 1995. Measuring Energy Efficiency in the United States' Economy: A Beginning. U.S. Department of Energy. DOE/EIA-0555(95)/2. October 2005. http://tonto.eia.doe.gov/ftproot/consumption/0555952.pdf.

Energy Information Administration (EIA). 1996. Residential Energy Consumption Survey Quality Profile. U.S. Department of Energy. March 1996. DOE/EIA-0555(96)/1.

Energy Information Administration (EIA). 1997. " $25^{\text {th }}$ Anniversary of the Oil Embargo." U.S. Department of Energy. http://www.eia.doe.gov/emeu/25opec/anniversary.html.

Energy Information Administration (EIA). 1999. "A Look at Residential Energy Consumption in 1997." U.S. Department of Energy. November 1999. Accessed from:

www.eia.doe.gov/pub/pdf/consumption/063297.pdf.

Energy Information Administration (EIA). 2004a. Annual Energy Outlook 2004 with Projections to 2025. U.S. Department of Energy. DOE/EIA-0383(2004). www.eia.doe.gov/emeu/aer.

Energy Information Administration (EIA). 2004b. Residential Energy Consumption 2001. U.S. Department of Energy. Accessed at www.eia.doe.gov/emeu/recs/recs2001/detail tables.html (housing characteristics), and www.eia.doe.gov/emeu/recs/recs2001/detailcetbls.html (consumption and expenditures). 
Energy Information Administration (EIA). 2004c. Emissions of Greenhouse Gases in the United States 2003. U.S. Department of Energy. http://www.eia.doe.gov/oiaf/1605/ggrpt/carbon.html. Accessed 20 September 2005.

European Commission. 2000. COLD II. The Revision of Energy Labeling and Minimum Energy Efficiency Standards for Domestic Refrigeration Appliances. Contractor ADEME. Final Report December 2000.

European Commission. 2003. External Costs: Research Results on Socio-Environmental Damages Due to Electricity and Transport. EUR 20198. www.externe.info/externpr.pdf.

European Environment Agency (EEA). 2001a. "Policy Issue: Do European Households Consume Less Energy?" Accessed from: http://themes.eea.eu.int/Sectors and activities/households/indicators/energy/index html.

European Environment Agency (EEA). 2001b. "Indicator Factsheet Signals 2001 - Chapter Households." Accessed from http://themes.eea.eu.int/Sectors and_activities/households/indicators/energy/hh06households.pdf.

Etzioni, Amitai. 1998. "Voluntary Simplicity: Characterization, Select Psychological Implications, and Societal Consequences." Journal of Economic Psychology 19:619-643.

Fawcett, Tina. 2003. "Carbon Rationing, Energy Efficiency, and Equity." Proceedings of the 2003 ECEEE Summer Study on Energy Efficiency in Buildings. San Raphael, France. European Council for an Energy-Efficient Economy.

Friends of the Earth Netherlands c.1998 Sustainable Consumption: A Global Perspective. FOE Discussion Paper.

Gaura, Maria Alicia, and Caroline Zinko. 1999.” Invasion of the Monster Homes. Silicon Valley trend spreads - raze a small house, build a mansion." San Francisco Chronicle, 8 November 1999. www.sfgate.com/cgi-bin/article.cgi?file=/chronicle/archive/1999/11/08/MN68431.DTL.

Goodwin, Neva et al., ed. 1997 "The Consumer Society.” Washington D.C.: Island Press.

Golove, William H., and Joe Eto. 1996. Market Barriers to Energy Efficiency: A Critical Reappraisal of the Rationale for Public Policies to Promote Energy Efficiency. LBNL-38059. Lawrence Berkeley National Laboratory.

Herring, Horace. 1998. "Does Energy Efficiency Save Energy: The Economists Debate." Milton Keynes: Energy and Environmental Resources Unit, Open University.

Herring, Horace. 2006. "Energy Efficiency-A Critical View.” Energy 31 (1): 10-20. Electronic edition (preprint).

Howarth, Richard B., Brent M. Haddad, and Bruce Paton. 2000. "The Economics of Energy Efficiency: Insights from Voluntary Participation Programs.” Energy Policy 28 (6-7): 477-486. 
Hungerford, David. 2004. Living Without Air Conditioning in a Hot Climate: Thermal Comfort in Social Context." Proceedings of the 2004 ACEEE Summer Study for Energy Efficiency in Buildings. Washington, D.C.: ACEEE.

Intergovernmental Panel for Climate Change (IPCC) 2001. Third Assessment Report. www.ipcc.ch/.

Jackson, T., and L. Michaelis. 2003. "Policies for Sustainable Consumption." A Report to the Sustainability Development Commission [UK].

www.sdcommission.org.uk/news/resource_download.php?attach_id=OA492PF-KAOQ5IHEAICDK6-H10C8GA.

Jeeninga, Harm, and P.F. Huenges Wajer Boudewijn. 1999. "Domestic Electricity Consumption and Lifestyle.” In Proceedings of the ECEEE Summer Study, 1999. Vol. Panel 3, 7. European Council for an Energy Efficient Economy. www.eceee.org/library links/proceedings/1999/pdf99/Panel3/3-07.pdf.

Jelsma, Jaap. 1999. “Towards a Sustainable Society: The Moralising of Machines?” San Diego, California.

Jelsma, Jaap. 2001. Presentation at the 2001 Summer School on Consumption, Everyday Life, and Sustainability. Lancaster, U.K.

Jelsma, J. 2004. "The Engineering Approach and Social Aspects of Energy Use: Mind the Gap, But Can It Be Closed?" Proceedings from the 2004 ACEEE Summer Study on Energy Efficiency in Buildings. American Council for an Energy Efficient Economy. Washington, D.C.: ACEEE.

Johnson, Samuel. 1759. Rasselas and Other Tales. ed. Gwin J. Kolb, vol. XVI of the Yale Edition of the Works of Samuel Johnson. New Haven: Yale University Press. [1990].

Kempton, Willett, and Christopher Payne. 1997. "Cultural and Social Evolutionary Determinants of Consumption." pp 116-123. In P. C. Stern, T. Dietz, V. W. Ruttan, R. H. Socolow, and J. L. Sweeney (editors), Environmentally Significant Consumption: Research Directions. Washington, D.C.: National Academy Press.

Laitner, John A. “Skip.” 2004. "How Far Energy Efficiency?” In Proceedings of the 2004 ACEEE Summer Study on Energy Efficiency in Buildings. Pacific Grove, California. Washington D.C.: American Council for an Energy Efficient Economy.

Laurence, Michael T. 2004. "Changes in the Patterns of Energy Consumption and Expenditures Over the Past Quarter Century." In Proceedings of the 2004 ACEEE Summer Study on Energy Efficiency in Buildings. Pacific Grove, California. Washington D.C.: American Council for an Energy Efficient Economy.

Loisos, George, and Susan Ubbelohde. 1998. "The Summer Comfort House: A Prototype Compressorless House for Transitional California Housing. In Proceedings of the ACEEE 1998 Summer Study. Pacific Grove, California. Washington D.C.: American Council for an Energy Efficient Economy.

Lutzenhiser. L. 1993. "Social and Behavioral Aspects of Energy Use." Annual Review of Energy and Environment. 18:247-289. 
McWhinney, M., A. Fanara, R. Clark, C. Herschberg, R. Schmeltz, and J. Roberson. 2005. "ENERGY STAR Product Specification Development Framework: Using Data and Analysis to Make Program Decisions.” Energy Policy 33(12).

Meier, Alan, and James E. Hill. 1997. "Energy Test Procedures for Appliances." Energy and Buildings 26 (1): 23-33.

Meier, Alan. 2000. Editorial: "Living in a Carbon-Constrained World." Home Energy 17. Available at: http://homeenergy.org/archive/hem.dis.anl.gov/eehem/00/000301.html.

Meier, Alan. 2003. "The Future of Energy Star and Other Voluntary Energy Efficiency Programmes.” IEA/EET Working Paper. EET/2003/02. March 2003. www.iea.org/dbtwwpd/textbase/papers/2003/wpaper.pdf.

Mick, David, and Susan Fournier. 1998. "Paradoxes of Technology: Consumer Cognizance, Emotions, and Coping Strategies.” Journal of Consumer Research 25 (2): 123-143.

Moezzi, Mithra. 1998. "The Predicament of Efficiency." In Proceedings of the 1998 ACEEE Summer Study on Energy Efficiency in Buildings. Pacific Grove, California. Washington D.C.: American Council for an Energy Efficient Economy. Available at http://enduse.lbl.gov/Info/ACEEE-Pred.pdf.

Moezzi, Mithra, 2000. "Decoupling Energy Efficiency from Energy Consumption," Energy and Environment 11 (5): 521-537.

Nader, Laura. 1981. "Barriers to Thinking New about Energy" Physics Today February 1981.

National Association of Home Builders (NAHB). 2003. Housing Facts: Figures and Trends 2003. National Association of Home Builders: Washington, D.C.

National Association of Home Builders (NAHB). 2004. Housing Facts: Figures and Trends 2004. National Association of Home Builders: Washington, D.C.

Nørgård, Jørgen S. 2000. "Models of Energy Savings: The Battlefield of Environmental Planning." International Journal of Global Energy Issues. Vol. 13, Nos. 1-3, pp. 102-122.

Nørgård, Jørgen S. 2005. “Consumer Efficiency in Conflict with GDP Growth.” Forthcoming, in Ecological Economics.

Nozzi, Dom. 2002. "The Emergency of Scrape-Offs and Monster Homes," at http://user.gru.net/domz/scrape.htm (personal web page, accessed September 2004).

Oreszczyn, Tadj. 2004. "Our Innate Ability to Think of New Ways to Use Energy." Energy and Environment 15 (6): 1011-1014(4).

Prahl, Duncan. 2000. "Analysis of Energy Consumption, Rating Score, and House Size." Washington D.C.: U.S. Green Building Council.

Rudin, Andrew. 1992. "The Consequences of Demand-Side Management" Engineered Systems January/February. 
Samiuallah, Shahana, David Hungerford, and Adrienne Kandel. 2002. "Do Central Air Conditioner Rebates Encourage Adoption of Air Conditioning." In Proceedings of the 2002 Summer Study of the American Council for Energy Efficient Buildings. Washington, D.C.: ACEEE.

Schor, Juliet. 1998. The Overspent American: Upscaling, downshifting and the new consumer. New York: Basic Books.

Shove, Elizabeth, and Harold Wilhite. 1999. "Energy Policy: What it Forgot and What it Might Yet Recognize.” In Proceedings of the ECEEE Summer Study. 1999. Vol. 1, 16. European Council for an Energy Efficient Economy. www.eceee.org/library_links/proceedings/1999/pdf99/Panel1/1-16.pdf.

Shove, Elizabeth. 1998. "Gaps, Barriers and Conceptual Chasms: Theories of Technology Transfer and Energy in Buildings.” Energy Policy 26 (15): 1105-1112.

Shove, Elizabeth. 2003. Comfort, Cleanliness and Convenience: The social organization of normality. Oxford: Berg Publishers.

Smith, Adam. 1776. The Wealth Of Nations. New York: Penguin Classics.

Springer, David. 2003. "Kicking The Residential Air Conditioner Habit." Home Energy. July/August 2003. Available at http://www.homeenergy.org/20-4.html.

Stein, Jeff Ross. 1997a "Home Energy Rating Systems: Actual Use May Vary." Home Energy. September/October 1997. http://homeenergy.org/archive/hem.dis.anl.gov/eehem/97/970910.html.

Stein, Jeff Ross. 1997b. “Accuracy of Home Energy Rating Systems.” Lawrence Berkeley National Laboratory. LBL-40394. UC-1600. http://eetd.lbl.gov/EA/Reports/40394/40394-0.

Tobiasson, Wendy, Fred Sebold, Jean Shelton, and Glen Sharp. 2004. "Teamwork in the Assessment of the Residential Market: California's Consortium Residential Appliance Saturation Survey." In Proceedings of the 2004 Summer Study of the American Council for an Energy Efficient Economy. Washington, D.C.: ACEEE.

Turiel, Isaac. 1997. "Present Status of Residential Appliance Energy Efficiency Standards — An International Review." Energy and Buildings 26 (1): 5-15.

Turiel, Isaac, Terry Chan, and James E. McMahon. 1997. "Theory and Methodology of Appliance Standards." Energy and Buildings 26 (1): 35-44.

U.S. DOE 1997. Final Rule: Refrigerators, Refrigerator-Freezers, and Freezers. 10 CFR Part 430. Federal Register 62(81):23101-23116. April 28, 1997.

U.S. DOE Annual Energy Outlook 2002. Table 1.5, Energy Consumption and Expenditures Indicators, 1949-2001.

U.S. DOE Emissions of Greenhouse Gases in the United States 2000.

www.eia.doe.gov/oiaf/1605/ggrpt/carbon.html (accessed 10 December 2002). 
U.S. Census Bureau.2003. C-25 Series (Characteristics of New Housing). www.census.gov/const/C25Ann/sftotalmedavgsqft.pdf.

Veblen, Thorstein, 1899. The Theory of the Leisure Class. Penguin Classics.

Vieira, R., D. Parker, J. Klongerbo, J. Sonne, and J. Cummings. 1996. "How Contractors Really Size Air Conditioners.” Florida Solar Energy Center. www.fsec.ucf.edu/bldg/pubs/ACsize/.

Wilhite, H. and J.S. Nørgård. 2004. "Equating Efficiency with Reduction: A Self-Deception in Energy Policy.” Energy \& Environment 15 (6): 991-1010.

Wilk, Richard. 2002. "Culture and Energy Consumption," in Energy, Science, Policy and the Pursuit of Sustainability. Robert Bent, Lloyd Orr, and Randall Baker, eds. Island Press: Washington D.C.

Wordspy. 2004. www.wordspy.com/words/supersize.asp (accessed September 2004).

Wray, C. P., and M. H. Sherman. 2001. "Residential Commissioning to Assess Envelope and HVAC System Performance." In Proceedings - Performance of Exterior Envelopes of Whole Buildings VIII Conference. Clearwater Beach, Florida, December 2001. 


\section{Glossary}

ACEEE American Council for an Energy Efficient Economy

AFUE Annual Fuel Utilization Efficiency

AV

Adjusted Volume

CAC

Central Air Conditioner

CHEERS California Home Energy Efficiency Rating System

DOE Department of Energy

ECEEE European Council for an Energy Efficient Economy

EIA Energy Information Administration

EPA Environmental Protection Agency

GHG Greenhouse Gas

HERS Home Energy Rating System

IOU Investor Owned Utility

IPCC Intergovernmental Panel on Climate Change

LEED Leadership in Energy and Environmental Design

MBTU Million British Thermal Unit

MEC Model Energy Code

NAECA National Appliance Energy Conservation Act

NAHB National Association of Home Builders

PC Personal Computer

PGE Portland Gas and Electric

RASS Residential Appliance Saturation Survey

RECS Residential Energy Consumption Survey

TTD Through the Door

UEC Unit Energy Consumption

VBG Vermont Built Green 